\title{
Biotransformation and Sorption of Trace Organic Compounds in Biological Nutrient Removal Treatment Systems
}

Narasimman Lakshminarasimman ${ }^{\mathrm{a}}$, Oscar Quiñones ${ }^{\mathrm{b}}$, Brett J. Vanderford ${ }^{\mathrm{b}}$, Pablo Moreno-

$$
\mathrm{Campo}^{\mathrm{c}} \text {, Eric V. Dickenson }{ }^{\mathrm{b}} \text {, Drew C. McAvoy }{ }^{\mathrm{a}^{*}}
$$

a. Department of Chemical and Environmental Engineering, University of Cincinnati, Cincinnati, OH 45221, USA

b. Water Quality Research and Development Division, Southern Nevada Water Authority, Henderson, NV 89015, USA

c. Cranfield Water Science Institute, Cranfield University, Cranfield, Beds, MK43 0AL,UK

*Corresponding author:

Drew C. McAvoy

Department of Chemical and Environmental Engineering,

University of Cincinnati, Cincinnati, OH 45221, USA

E-mail: $\underline{\text { mcavoydm@ucmail.uc.edu }}$

\section{Highlights}

- Biotransformation rate and sorption distribution coefficient of TOrCs in different redox conditions

- Biotransformation rate coefficients affected by redox condition and SRT

- High correlation of sorption distribution coefficients in anaerobic and anoxic sludge

- Fate parameters useful in predictive models 


\section{Graphical Abstract}

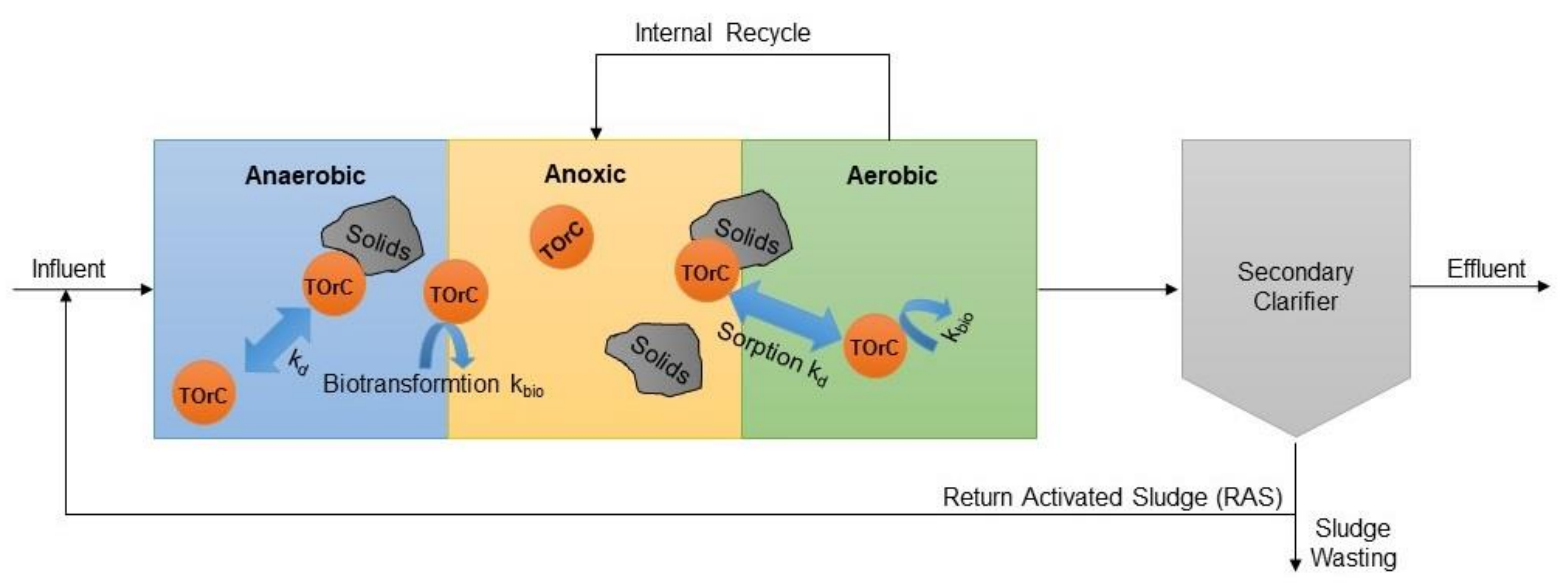




\begin{abstract}
This study determined biotransformation rates $\left(\mathrm{k}_{\mathrm{bio}}\right)$ and sorption-distribution coefficients $\left(\mathrm{K}_{\mathrm{d}}\right)$ for a select group of trace organic compounds (TOrCs) in anaerobic, anoxic, and aerobic activated sludge collected from two different biological nutrient removal (BNR) treatment systems located in Nevada (NV) and Ohio (OH) in the United States (US). The NV and OH facilities operated at solids retention times (SRTs) of 8 and 23 days, respectively. Using microwave-assisted extraction, the biotransformation rates of the chosen TOrCs were measured in the total mixed liquor. Sulfamethoxazole, trimethoprim, and atenolol biotransformed in all three redox regimes irrespective of the activated sludge source. The biotransformation of $N, N$ diethyl-3-methylbenzamide (DEET), triclosan, and benzotriazole was observed in aerobic activated sludge from both treatment plants; however, anoxic biotransformation of these three compounds was seen only in anoxic activated sludge from NV. Carbamazepine was recalcitrant in all three redox regimes and both sources of activated sludge. Atenolol and DEET had greater biotransformation rates in activated sludge with a higher SRT (23 days), while trimethoprim had a higher biotransformation rate in activated sludge with a lower SRT (8 days). The remaining compounds did not show any dependence on SRT. Lyophilized, heat inactivated sludge solids were used to determine the sorption-distribution coefficients. Triclosan was the most sorptive compound followed by carbamazepine, sulfamethoxazole, DEET, and benzotriazole. The sorption-distribution coefficients were similar across redox conditions and sludge sources. The biotransformation rates and sorption-distribution coefficients determined in this study can be used to improve fate prediction of the target TOrCs in BNR treatment systems.
\end{abstract}

Keywords: Trace organic compounds, pharmaceuticals and personal care products, biotransformation, sorption, biological nutrient removal treatment 


\section{Introduction}

Consumer product ingredients have been identified as a contributor to anthropogenic pollution. With the advancement of analytical techniques, a wide range of trace organic compounds (TOrCs) are now being detected in different environmental matrices. While these compounds are introduced into the environment through a number of pathways, wastewater treatment plant (WWTP) effluents are a major source of these chemicals in receiving waters (Drewes and Shore, 2001). Since wastewater treatment plants were originally designed to remove conventional pollutants (solids, bulk organics, and nutrients), the removal of TOrCs occurs to various degrees by virtue of the treatment process and the physico-chemical properties of the compound (Rogers, 1996). The major mechanisms of removal are biotic transformation or abiotic processes such as sorption, volatilization, isomerization, and hydrolysis (Pomies et al., 2013).

Mathematical models for assessing the fate of TOrCs in wastewater treatment are effective tools for process design, optimization of existing processes, or augmentation using tertiary treatment processes for improved effluent quality (Clouzot et al., 2013). Several modeling frameworks such as ASTREAT (McAvoy et al., 1999), TOXCHEM+ (Melcer et al., 1999), WATER9 (U.S. EPA, 2001), and SimpleTreat (Struijs et al., 2016) have been developed to predict the removal of organic compounds in conventional activated sludge (CAS) systems. The ASM-X model has also been developed to include an anoxic process for denitrifying systems (Plosz et al., 2010).

Biotransformation and sorption are typically the two important fate mechanisms for assessing the removal of organic compounds in WWTPs. These fate processes have predominantly been studied in aerobic activated sludge from CAS treatment systems. State-of-the art reviews by Clouzot et al. (2013) and Pomies et al. (2013) have discussed the absence of fate parameters in 
different redox conditions for micropollutant modeling. Biological nutrient removal (BNR) treatment processes, like the $\mathrm{A}^{2} \mathrm{O}$ design, employ anaerobic and anoxic zones in addition to an aerobic zone to promote the growth of phosphorus accumulating organisms (PAO) and denitrifiers, which are responsible for the removal nitrogen and phosphorus from wastewater. It has been hypothesized that BNR treatment systems may create favorable conditions for TOrC removal because of the different redox regimes that harbor a diverse consortium of microorganisms and enzyme pools to promote biotransformation (Xue et al., 2013). Nutrient removal processes may also be more effective in reducing the toxicity of treated effluents on aquatic life forms when compared to CAS treatment systems (Parker et al., 2014). In particular, the removal of estrogenicity has been reported in anaerobic, anoxic, and aerobic redox conditions in a pilot-scale University of Cape Town BNR (UCT-BNR) design (Ogunlaja and Parker, 2015). Hence, it is worthwhile to study fate mechanisms of TOrCs in BNR treatment systems and model these systems to advance our current understanding of their removal.

In this study seven TOrCs were chosen for investigation: atenolol (ATN), benzotriazole (BTA), carbamazepine (CBZ), N, N-diethyl-3-methylbenzamide (DEET), sulfamethoxazole (SMX), trimethoprim (TMP) and triclosan (TCS). These TOrCs were selected because they: (1) are commonly detected in wastewater effluents throughout the world including Europe (Loos et al., 2013), Germany (Ternes et al., 1998), South Korea (Behera et al., 2011), Spain (Rosal et al., 2010; Santos et al., 2007), Switzerland (Eggen et al., 2014), and the United States (Salveson et al. 2012); (2) have been identified as priority contaminants of concern in several priority lists (Higgins et al., 2010; Diamond et al. 2010), and (3) exposure to these compounds has been known to elicit toxic effects in aquatic life forms. DEET, a biocide used in insect repellants, has been shown to cause reproductive disorders after prolonged environmental exposures 
(Manikkam et al., 2012). Isidori et al. (2005) reported sulfamethoxazole, an antibiotic, to cause chronic toxicity to aquatic organisms at part-per-billion levels. Tatarazako et al. (2004) has shown triclosan, an antibacterial agent, to be highly toxic to aquatic biota. The corrosion inhibitor benzotriazole has been shown to present an estrogenic response in bioassays (Harris et al., 2007) and exert toxicity to plants (Cancilla et al., 1997), while the accumulation of carbamazepine and triclosan have been observed in fish liver tissue (Diamond et al. 2010).

The primary objective of this study was to experimentally derive biotransformation kinetic rates and sorption-distribution coefficients of a select group of TOrCs in activated sludge collected from three redox conditions at two different BNR treatment plants with an $\mathrm{A}^{2} \mathrm{O}$ configuration. In activated sludge systems, the mechanism of biodegradation is often a topic of contention (Pomies et al., 2013). Most studies measure biotransformation only in the aqueous phase, while the biodegradation of an organic compound may occur in the aqueous phase or on the solids while being sorbed. Compounds may also desorb from the solids and become bioavailable for degradation in the aqueous phase. Identifying the biodegradation compartment is challenging because the compound, depending on its physical properties, may be present in both the solid and aqueous phases at a given time. Hence in this study, biotransformation rates were determined as the total compound loss in the mixed liquor by using microwave-assisted extraction. The sorption-distribution coefficients were determined using lyophilized, heat inactivated sludge solids to reduce the occurrence of biotransformation during sample equilibrium. The effect of redox conditions and solids retention time (SRT) were also assessed with respect to biotransformation and sorptive fate of the target TOrCs. 


\section{Methodology}

\subsection{Materials}

All of these compounds were purchased from Sigma Aldrich (Purity > 97\%). The structure of these target compounds, their physico-chemical properties, and location of the isotopic labels in the internal standards are provided in the Supplementary Material (Table S-1 and S-2). Activated sludge for the biotransformation and sorption experiments were obtained from two BNR treatment plants located in Ohio $(\mathrm{OH})$ and Nevada $(\mathrm{NV})$. Both treatment plants were configured in the $\mathrm{A}^{2} \mathrm{O}$ process design (Figure 1). NV is a 30 MGD BNR treatment facility operated at an SRT of 8 days, while $\mathrm{OH}$ is a 9 MGD BNR treatment facility operated at an SRT 23 days. The influent wastewater to both of the wastewater treatment plants is primarily residential. The activated sludge samples were collected from the effluent of each unit process (anaerobic, anoxic, and aerobic) when the treatment plants were operating under normal, steady state conditions. The operational parameters reported by the treatment plants during the time of sampling are provided in the Supplementary Material (Table S-3 and S-4). Activated sludge from both $\mathrm{NV}$ and $\mathrm{OH}$ were transported to the laboratory on ice and processed within 24 hours of collection. 


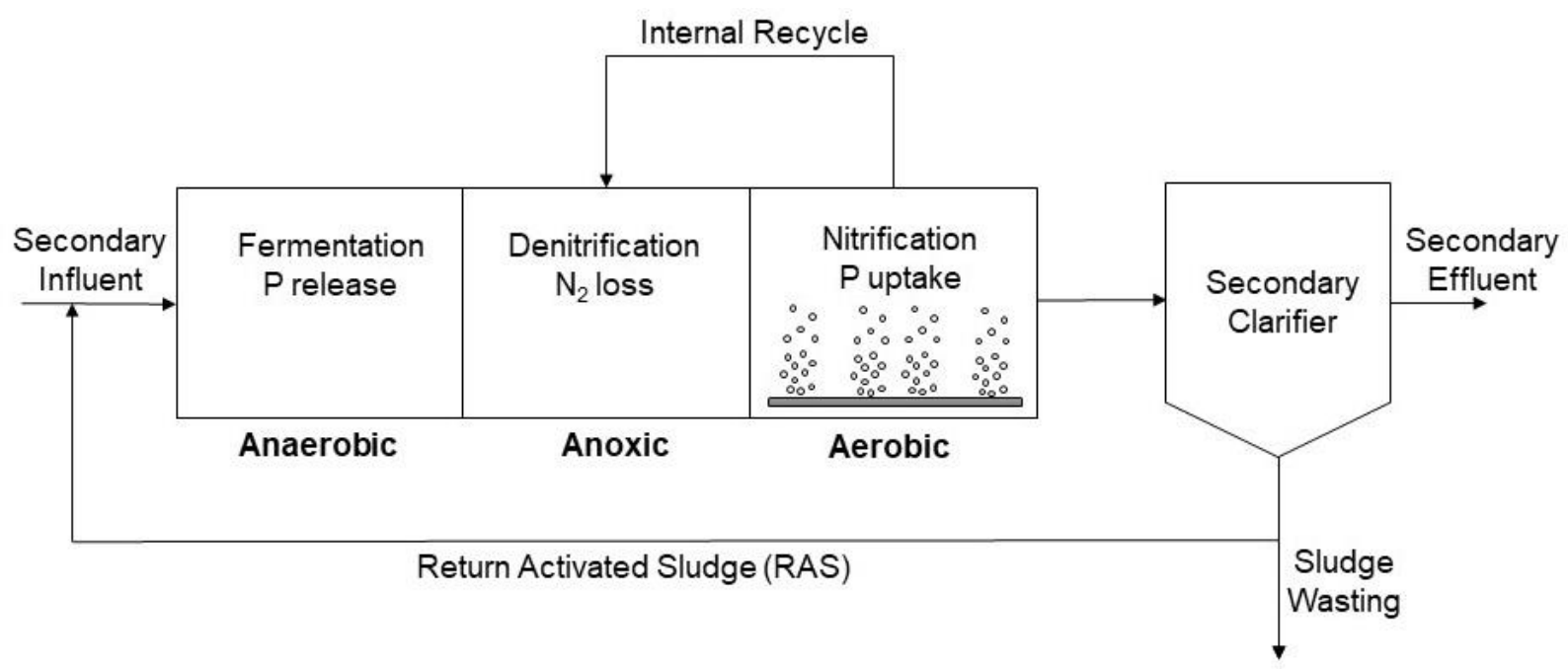

Figure 1. Process diagram for $\mathrm{A}^{2} \mathrm{O} B N R$ treatment

\subsection{Biotransformation Experiment}

\subsubsection{Experimental Procedure}

After receiving samples in the laboratory, $10 \mathrm{~L}$ of activated sludge was placed in four separate stainless steel reactors. Two of the four reactors were used as duplicate biotic reactors, one was used as an abiotic reactor (biocide solution containing $10 \mathrm{mM}$ each of $\mathrm{NaN}_{3}, \mathrm{BaCl}_{2}$ and $\mathrm{NiCl}_{2}$ ), and the other as an experimental control (deionized water). All of the reactors were buffered with $\mathrm{NaHCO}_{3}$ to a final equivalence of $3 \mathrm{mM}$. A nutrient solution was spiked in the aerobic reactors (5 mg NH $3-\mathrm{N} / \mathrm{L}$ and $10 \mathrm{mg} / \mathrm{L} \mathrm{PO}_{4}-\mathrm{P} / \mathrm{L}$ ) to assess nitrification and phosphorus uptake, and in the anoxic reactors (30 $\mathrm{mg} \mathrm{NO}_{3}-\mathrm{N} / \mathrm{L}$ every 12 hours) to ensure denitrification. Relevant redox conditions $(\mathrm{DO}>4 \mathrm{mg} / \mathrm{L}$ for aerobic and $\mathrm{DO}<0.1 \mathrm{mg} / \mathrm{L}$ for anaerobic and anoxic) were maintained by bubbling compressed air or nitrogen gas through the reactors. The reactors were equilibrated for an hour prior to spiking the target TOrCs. The TOrC stock solution was prepared in $100 \%$ methanol and stored at $2{ }^{\circ} \mathrm{C}$ in amber glass bottles until use. The stock solution was brought to room temperature prior to preparation of the spiking solution, which was 
prepared in ultrapure water to achieve an equivalent of $10 \mu \mathrm{g} / \mathrm{L}$ of each TOrC in the reactors at time zero. The methanol addition from the TOrC spiking solution contributed about $7.5 \mathrm{mg}-\mathrm{C} / \mathrm{L}$ in the system. At specific time points, samples $(500 \mathrm{~mL})$ were collected for TOrC analysis in amber bottles containing a final equivalence of $1 \mathrm{~g} / \mathrm{L} \mathrm{NaN}_{3}$ and $0.5 \mathrm{~g} / \mathrm{L}$ ascorbic acid as a preservative. Aerobic and anoxic experiments were run for 1-3 days, while the anaerobic experiments were run for 7 days because of expected slower kinetics. The buffer, nutrient spike, laboratory water, and activated sludge were also analyzed for the target TOrCs to determine background concentrations. The TOrC concentrations (C) measured at different time points were then divided by the measured initial TOrC concentration in the reactor and plotted against time. The results were fit to the following kinetic model:

$$
d C / d t=-k_{b i o}[C][X]
$$

where, $\mathrm{k}_{\mathrm{bio}}$ is the pseudo first-order biotransformation rate constant (L/g-day) with aa assumed constant biomass concentration in the system (X as TSS or VSS).

\subsubsection{Analytical Methods}

Conventional Parameters: The conventional parameters $\mathrm{pH}$, dissolved oxygen (DO), total and volatile suspended solids (TSS/VSS), dissolved organic carbon (DOC), soluble and particulate chemical oxygen demand (sCOD/pCOD), ammonia $\left(\mathrm{NH}_{3}-\mathrm{N}\right)$, nitrite $\left(\mathrm{NO}_{2}-\mathrm{N}\right)$, nitrate $\left(\mathrm{NO}_{3}-\mathrm{N}\right)$ and phosphate $\left(\mathrm{PO}_{4}-\mathrm{P}\right)$ were analyzed at various time points in the biotic reactors using Standard Methods (provided in the Supplementary Material, Table S-7). Presence of the biocide in the abiotic control reactor interfered with the $\mathrm{COD}, \mathrm{NO}_{2}-\mathrm{N}, \mathrm{NO}_{3}-\mathrm{N}$, and $\mathrm{PO}_{4}-\mathrm{P}$ analysis. Hence, only $\mathrm{pH}, \mathrm{DO}, \mathrm{TSS} / \mathrm{VSS}$, and DOC were analyzed in the abiotic control. The conventional parameter samples were preserved at $\mathrm{pH} 2$ with concentrated sulfuric acid and stored at $2{ }^{\circ} \mathrm{C}$ until being 
analyzed. The samples for soluble conventional parameters analyses were filtered using a $1.2 \mu \mathrm{m}$ glass fiber filter (Whatman GF/C).

$\underline{\text { TOrC Analysis: }}$ TOrC extraction and analysis in the total mixed liquor sample consisted of three steps. Firstly, the internal standard solution was added to $10 \mathrm{~mL}$ of sample and mixed with 10 $\mathrm{mL}$ of methanol. The target compounds were then extracted from the activated sludge/methanol mixture using microwave-assisted extraction (MAE) at $120{ }^{\circ} \mathrm{C}$ for $20 \mathrm{~min}$ using an EthosUp high performance microwave digestion system from Milestone (Shelton, CT). The MAE liquor was then diluted to $1-\mathrm{L}$ in reagent-grade water and the analytes were isolated via automated solidphase extraction (ASPE) using HLB (6-mL and 200-mg) cartridges from Waters Corporation (Milford, MA) and an AutoTrace ${ }^{\mathrm{TM}}$ ASPE (Dionex Corporation, Sunnyvale, CA). The SPE cartridges were sequentially preconditioned with $5 \mathrm{~mL}$ of methyl tert-butyl ether (MTBE), $5 \mathrm{~mL}$ of methanol, and $5 \mathrm{~mL}$ of reagent-grade water. Each sample was loaded onto a cartridge at 15 $\mathrm{mL} / \mathrm{min}$ and then rinsed with $5 \mathrm{~mL}$ of reagent-grade water and subsequently dried under a nitrogen stream for $30 \mathrm{~min}$. Each cartridge was eluted with $5 \mathrm{~mL}$ of methanol followed by $5 \mathrm{~mL}$ of $10 / 90(\mathrm{v} / \mathrm{v})$ methanol/MTBE and the extract was evaporated under a $\mathrm{N}_{2}$ stream to a $500 \mu \mathrm{L}$ final volume. The final step was instrumental analysis of the ASPE extracts using isotope dilution liquid chromatography-tandem mass spectrometry (Vanderford and Snyder, 2006). All analytes were separated by a $100 \times 4.6 \mathrm{~mm}$ Onyx Monolithic C18 column (Phenomenex, Torrance, CA) at $40{ }^{\circ} \mathrm{C}$. Chromatographic separation was accomplished with a binary gradient of $5 \mathrm{mM}$ ammonium acetate (v/v) in reagent-grade water (A) and 100\% methanol (B) at a flow rate of $0.8 \mathrm{~mL} / \mathrm{min}$. The target analytes and isotopic surrogates were quantified by tandem mass spectrometry using an API 4000 triple-quadrupole mass spectrometer (Applied Biosystems, Foster City, CA). Depending on the compound, either an ESI negative mode (TCS) or ESI 
positive mode (ATN, BTA, CBZ, DEET, SMX, TMP) was used for quantitation. The analytical parameters for the target compounds are provided in the Supplementary Material (Table S-5).

\subsection{Sorption Experiment}

\subsubsection{Sludge Handling Procedure}

The inactivation of activated sludge was carried out following the procedure described in Kerr et al. (2000). Upon receipt of the activated sludge samples in the laboratory, the solids were allowed to settle for an hour in their sample containers and the supernatant was discarded. The remaining thickened solids solution was centrifuged at $2800 \mathrm{~g}$ for $5 \mathrm{~min}$ in $50 \mathrm{~mL}$ polypropylene centrifuge tubes. The supernatant was discarded and $30 \mathrm{~mL}$ of deionized (DI) water was added. The centrifuge tubes were then shaken by hand and centrifuged again at $2800 \mathrm{~g}$ for $5 \mathrm{~min}$. This DI water washing step was done three times. After the final washing and decantation, the solids were placed in a freeze drying dish and pre-frozen at $-20^{\circ} \mathrm{C}$. Pre-frozen solids were then lyophilized in a benchtop LABCONCO freeze dryer at $-60{ }^{\circ} \mathrm{C}$ for at least 24 hour. After lyophilization the freeze dried solids were ground lightly using a mortar and pestle to break down the bulk solids. For inactivation, the solids were placed in an oven at $103{ }^{\circ} \mathrm{C}$ overnight prior to being stored in clean amber glass bottles. Prior to being used in the sorption experiments, a portion of the freeze dried solids were again heated at $103{ }^{\circ} \mathrm{C}$ in an oven overnight. A $90 \mathrm{mg}$ sample of the dried solids were carefully weighed into $50-\mathrm{mL}$ polypropylene centrifuge tubes and $30 \mathrm{~mL}$ of synthetic wastewater was introduced to achieve a final solids concentration of approximately $3 \mathrm{~g} / \mathrm{L}$. The synthetic wastewater was composed of: $6.5 \mathrm{mg} / \mathrm{L} \mathrm{KH}_{2} \mathrm{PO}_{4} ; 22 \mathrm{mg} / \mathrm{L}$ $\mathrm{K}_{2} \mathrm{HPO}_{4} ; 33 \mathrm{mg} / \mathrm{L} \mathrm{Na}_{2} \mathrm{HPO}_{4} ; 2 \mathrm{mg} / \mathrm{LNH}_{4} \mathrm{Cl} ; 22 \mathrm{mg} / \mathrm{L} \mathrm{MgSO}_{4} ; 36 \mathrm{mg} / \mathrm{L} \mathrm{CaCl}_{2} ; 0.3 \mathrm{mg} / \mathrm{L} \mathrm{FeCl}_{3} ;$ $300 \mathrm{mg} / \mathrm{L} \mathrm{NaHCO}$. The samples were centrifuged at $2800 \mathrm{~g}$ for $5 \mathrm{~min}$ and the supernatant removed using a pipet. This procedure was repeated two more times to remove any dissolved 
organic carbon that was released from the solids. The inactivated sludge was then re-suspended in synthetic wastewater and used immediately in the sorption experiments to minimize the potential for biodegradation.

\subsubsection{Sorption Experimental Procedure}

After the third washing step, synthetic wastewater was added to maintain a solids-to-liquid ratio of $3 \mathrm{~g} / \mathrm{L}$. A spike solution was prepared similar to the biotransformation experiment except that only five of the seven compounds (BTA, CBZ, DEET, SMX, TCS) were added in the sorption experiment. The reactors were spiked at five different concentrations $(0.5,1,2.5,5$ and $10 \mu \mathrm{g} / \mathrm{L}$ ) to develop sorption isotherms. After spiking the test compounds, the centrifuge tubes were thoroughly mixed by end-over-end hand rotation for approximately $30 \mathrm{~s}$. The centrifuge tubes were then equilibrated in a rotational tumbler at room temperature $\left(\sim 23^{\circ} \mathrm{C}\right)$ for $4 \mathrm{~h}$ (equilibrium time determined by Steven-Garmon et al. (2011) and Kerr et al. (2000)). Following equilibrium, the test vessels were centrifuged (2800 $\mathrm{g}$ for $5 \mathrm{~min}$ ) and $50 \mathrm{~mL}$ of centrate (aqueous phase) was transferred via a pipet into clean $60 \mathrm{~mL}$ sampling vials. The TOrC concentrations were measured only in the aqueous phase, and the solid phase TOrC concentrations were assumed to be the difference between the spiking concentration and the aqueous phase concentration. The solid phase concentrations were plotted against the measured aqueous phase concentrations and a linear regression analysis was performed to determine the sorption distribution coefficient (slope of the line fit through the origin) for each compound.

$$
K_{d}=\frac{C_{s o r} /\left(M L S S \times 10^{-3}\right)}{C_{s o l}}
$$

where, $\mathrm{K}_{\mathrm{d}}$ is the sorption-distribution coefficient (L/kg), MLSS - concentration of the mixed liquor suspended solids $(\mathrm{g} / \mathrm{L}), \mathrm{C}_{\mathrm{sor}}$ - concentration of TOrCs in the sorbed phase $(\mu \mathrm{g} / \mathrm{L}) \mathrm{C}_{\mathrm{sol}}-$ Concentration of TOrCs in the aqueous phase $(\mu \mathrm{g} / \mathrm{L})$. 


\subsubsection{TOrCs Extraction and Analysis}

Analytes from the aqueous phase were extracted using 150-mg hydrophilic-lipophilic balance (HLB) cartridges from Waters Corporation (Milford, MA). The SPE cartridges were first preconditioned with $10 \mathrm{~mL}$ of reagent-grade water followed by $50 \mathrm{~mL}$ of sample loading at 15 $\mathrm{mL} / \mathrm{min}$. The analytes were then eluted using $10 \mathrm{~mL}$ of acetonitrile in two $5 \mathrm{~mL}$ elution steps and collected in $10 \mathrm{~mL}$ calibrated centrifuge tube. The extracts were then concentrated by a gentle stream of nitrogen to a volume less than $1 \mathrm{~mL}$ and then brought up to exactly $1-\mathrm{mL}$ with acetonitrile. An Agilent G6410A Triple Quadrupole mass spectrometer was used for quantitation of the analytes. All of the compounds, except triclosan, were measured in ESI positive mode. Triclosan was measured in ESI negative mode. The analytes were separated using an Agilent ZORBAX C18 column $(2.1 \times 100 \mathrm{~mm})$ at $25^{\circ} \mathrm{C}$. Chromatographic separation was accomplished using a binary gradient of $0.1 \%$ formate in reagent-grade water (A) and $0.1 \%$ formate in acetonitrile (B) for the positive mode method and $5 \mathrm{mM}$ ammonium acetate in reagent-grade water and $5 \mathrm{mM}$ ammonium acetate in methanol for the negative mode method. An injection volume of $5 \mu \mathrm{L}$ at $500 \mu \mathrm{L} / \mathrm{mL}$ flow rate was used for all analyses. The analytical parameters for the target compounds are provided in the Supplementary Material (Table S-6).

\section{Results and Discussion}

\subsection{Biotransformation Kinetics}

\subsubsection{Analysis of Conventional Parameters}

The conventional parameters in six biotransformation experiments are discussed in the Supplementary Material (Section 4, Table S-8 and Figures S-1, S-2 and S-3). The conventional parameter monitoring revealed that the microbial process for each of the redox conditions (nitrification in aerobic, denitrification in anoxic, fermentation or phosphorus release in 
anaerobic) were operating properly. Monitoring these parameters also ensured that the biomass was active throughout the experiment.

\subsubsection{TOrCs Kinetics}

The pseudo first-order biotransformation rates $\left(\mathrm{k}_{\mathrm{bio}}\right)$ were normalized with the average TSS and VSS concentration over the duration of the experiment (Table 1). While the concentration of VSS better represents the biomass concentration, TSS was also included so that the rates could be compared with literature values. The biotransformation profiles for all the experiments can be seen in Figure S-4 (a-n) in the Supplementary Material. Minimal residual values $(<10 \%$ most of the times) and $\mathrm{R}^{2}$ values $>0.8$ show very good data fit for the kinetic model.

Results from the abiotic reactor, experimental control, and activated sludge before spiking are also provided in the Supplementary Material (Figures S-5 and S-6). Except for atenolol, all of the compounds remained stable in the abiotic kill control $\left(10 \mathrm{mM} \mathrm{NaN}+\mathrm{NiCl}_{2}+\mathrm{BaCl}_{2}\right.$ biocide $)$ with activated sludge. Atenolol degradation of approximately $40 \%$ occurred in the abiotic control during the course of the experiments (Supplementary Material, Figure S-1 c, d), suggesting either that the biocide used was ineffective for this compound or another fate mechanisms were involved. Hydrolysis was ruled out because atenolol was relatively stable in the experimental control reactor with buffered DI water. Sorption to activated sludge was also ruled out because the TOrCs analysis determined total mixed liquor concentration (i.e., inclusive of aqueous and solid phases). It was hypothesized that the enzymes responsible for degradation of atenolol was not inactivated with the biocide. To evaluate this hypothesis, methanol (8\% final concentration) was added to the abiotic control reactor and the kinetics were studied. Results from this experiment (Supplementary Material, Figure S-7) showed the atenolol concentration to decrease by only $15 \%$ over the course of 7 days, which is much less than the $40 \%$ loss observed 
without the methanol addition. These results confirm that the biocide used in this study only arrested the microbial respiration and the addition of methanol was needed to denature the enzymes responsible for degrading atenolol. 
Table 1. Biotransformation rates $\left(\mathrm{k}_{\mathrm{bio}} \pm 95 \% \mathrm{CI}\right.$ in $\mathrm{L} / \mathrm{g}_{\mathrm{TSS}}-$ day and $\left.\mathrm{L} / \mathrm{g}_{\mathrm{vss}}-\mathrm{day}\right)$ of the target $\mathrm{TOrCs}$ in activated sludge from three redox conditions in two BNR treatment plants, and a comparison with literature values.

TOrC

Kinetic

Parameter

OH $($ SRT $=23$ days $)$

NV $($ SRT $=8$ days $)$

Literature $\mathrm{k}_{\mathrm{bio}}$ in $\mathrm{L} / \mathrm{g}_{\mathrm{TSS}}-\mathrm{day}$ 


\begin{tabular}{|c|c|c|c|c|c|c|c|c|c|c|c|}
\hline & & & Anaerobic & Anoxic & Aerobic & Anaerobic & Anoxic & Aerobic & Anaerobic & Anoxic & Aerobic \\
\hline \multirow{9}{*}{$\begin{array}{c}\text { Group } 1 \\
\text { (Biotransformation } \\
\text { under all conditions) }\end{array}$} & \multirow{3}{*}{ ATN } & $\mathrm{L} / \mathrm{g}_{\mathrm{TSS}}$-day & $0.14 \pm 0.19$ & $2.56 \pm 0.01$ & $2.92 \pm 0.00$ & $0.17 \pm 0.06$ & $0.39 \pm 0.02$ & $1.61 \pm 0.12$ & \multirow{3}{*}{$1.7^{c}$} & \multirow{3}{*}{$0.43^{\mathrm{c}}$} & \multirow{3}{*}{$\begin{array}{c}1.5^{\mathrm{a}}, 3.28^{\mathrm{b}} .5 .28^{\mathrm{c}} \\
1.1-1.9^{\mathrm{d}}\end{array}$} \\
\hline & & $\mathrm{L} / \mathrm{g}_{\mathrm{vss}}-$ day & $0.42 \pm 0.18$ & $3.36 \pm 0.004$ & $3.58 \pm 0.12$ & $0.24 \pm 0.08$ & $0.54 \pm 0.05$ & $2.26 \pm 0.20$ & & & \\
\hline & & $R^{2}(R M S E)$ & $0.83(0.14)$ & $0.99(0.08)$ & $0.85(0.11)$ & $0.96(0.07)$ & $0.89(0.03)$ & $0.99(0.02)$ & & & \\
\hline & \multirow{3}{*}{ TMP } & L/g $\mathrm{g}_{\text {TSS }}$-day & $0.072 \pm 0.08$ & $0.14 \pm 0.02$ & $0.11 \pm 0.00$ & $0.24 \pm 0.02$ & $0.60 \pm 0.05$ & $0.53 \pm 0.04$ & \multirow{3}{*}{$0.22^{\mathrm{c}}$} & \multirow{3}{*}{ NA } & \multirow{3}{*}{$\begin{array}{c}5.04^{\mathrm{c}}, 0.22^{\mathrm{f}} \\
0.05-0.09^{\mathrm{g}}, 0.15^{\mathrm{h}}\end{array}$} \\
\hline & & $L / g_{\text {vss }}$-day & $0.024 \pm 0.01$ & $0.19 \pm 0.009$ & $0.14 \pm 0.00$ & $0.33 \pm 0.03$ & $0.81 \pm 0.11$ & $0.75 \pm 0.07$ & & & \\
\hline & & $R^{2}(R M S E)$ & $0.95(0.09)$ & $0.96(0.04)$ & $0.94(0.03)$ & $0.98(0.04)$ & $0.99(0.04)$ & $0.92(0.12)$ & & & \\
\hline & \multirow{3}{*}{ SMX } & $\mathrm{L} / \mathrm{g}_{\mathrm{TSS}}$-day & $0.01 \pm 0.02$ & $0.04 \pm 0.00$ & $0.14 \pm 0.02$ & $0.03 \pm 0.05$ & $0.06 \pm 0.03$ & $0.07 \pm 0.02$ & \multirow{3}{*}{$0.41^{\mathrm{j}}$} & \multirow{3}{*}{ NA } & \multirow{3}{*}{$\begin{array}{c}0.19-0.2^{\mathrm{f}}, 0.15^{\mathrm{h}}, \\
0.41^{\mathrm{j}}\end{array}$} \\
\hline & & L/g gss-day & $0.02 \pm 0.01$ & $0.05 \pm 0.009$ & $0.17 \pm 0.02$ & $0.05 \pm 0.07$ & $0.09 \pm 0.03$ & $0.11 \pm 0.02$ & & & \\
\hline & & $R^{2}(R M S E)$ & $0.88(0.03)$ & $0.82(0.04)$ & $0.92(0.04)$ & $0.83(0.09)$ & $0.94(0.02)$ & $0.84(0.04)$ & & & \\
\hline \multirow{2}{*}{$\begin{array}{c}\text { Group 2 } \\
\text { (No } \\
\text { biotransformation) }\end{array}$} & \multirow[b]{2}{*}{$\mathrm{CBZ}$} & $L / g_{\text {TSS }}$-day & \multirow[b]{2}{*}{ NB } & \multirow[b]{2}{*}{ NB } & \multirow[b]{2}{*}{ NB } & \multirow[b]{2}{*}{ NB } & \multirow[b]{2}{*}{ NB } & \multirow[b]{2}{*}{ NB } & \multirow[b]{2}{*}{$<0.02^{\mathrm{c}}$} & \multirow[b]{2}{*}{$<0.02^{\mathrm{c}}$} & \multirow{2}{*}{ 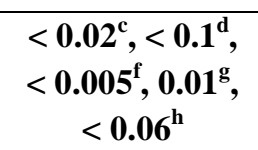 } \\
\hline & & 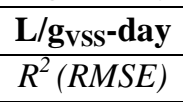 & & & & & & & & & \\
\hline \multirow{9}{*}{$\begin{array}{c}\text { Group } 3 \\
\text { (Biotransformation } \\
\text { dependent on redox } \\
\text { condition and SRT) }\end{array}$} & \multirow{3}{*}{ BTA } & $L / g_{\text {TSS }}$-day & \multirow{3}{*}{ NB } & \multirow{3}{*}{ NB } & $0.16 \pm 0.14$ & \multirow{3}{*}{ NB } & $0.15 \pm 0.02$ & $0.11 \pm 0.04$ & \multirow{3}{*}{$0.24^{\mathrm{e}}$} & \multirow{3}{*}{ NA } & \multirow{3}{*}{$0.22^{\mathrm{e}}$} \\
\hline & & L/g gss-day & & & $0.19 \pm 0.17$ & & $0.21 \pm 0.04$ & $0.15 \pm 0.06$ & & & \\
\hline & & $R^{2}(R M S E)$ & & & $0.54(0.11)$ & & $0.96(0.04)$ & $0.81(0.06)$ & & & \\
\hline & \multirow{3}{*}{ DEET } & $\mathrm{L} / \mathrm{g}_{\mathrm{TSS}}$-day & & & $4.43 \pm 0.05$ & & $0.02 \pm 0.03$ & $0.62 \pm 0.05$ & & & \\
\hline & & 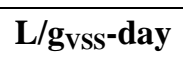 & NB & NB & $5.43 \pm 0.12$ & NB & $0.04 \pm 0.04$ & $0.87 \pm 0.09$ & NA & NA & $0.3^{\mathrm{a}}, 0.98^{\mathrm{c}}, 5.76^{\mathrm{i}}$ \\
\hline & & $R^{2}(R M S E)$ & & & $0.98(0.10)$ & & $0.59(0.03)$ & $0.99(0.08)$ & & & \\
\hline & & $\mathrm{L} / \mathrm{g}_{\mathrm{TSS}}$-day & & & $0.49 \pm 0.09$ & & $0.17 \pm 0.16$ & $0.31 \pm 0.02$ & & & \\
\hline & TCS & $L / g_{\text {vss }}$-day & NB & NB & $0.60 \pm 0.13$ & NB & $0.23 \pm 0.19$ & $0.44 \pm 0.04$ & $<0.02^{\mathrm{c}}$ & $<0.02^{\mathrm{c}}$ & $0.82^{c}, 1.3^{i}$ \\
\hline & & $R^{2}(R M S E)$ & & & $0.97(0.06)$ & & $0.92(0.19)$ & $0.82(0.03)$ & & & \\
\hline
\end{tabular}

NB - No biotransformation, NA - Not Available, RMSE - Root Mean Squared Error. References: a) Helbling et al. (2010); b) Horsing et al. (2011); c) Inyang et al. (2016); d) Wick et al. (2009); e) Mazioti et al. (2015); f) Abegglen et al. (2009); g) Fernandez-Fonataina et al. (2013); h) Suarez et al. (2010); i) Salveson et al. (2012); j) Polz et al. (2010) 
The compounds were classified into three groups based on their biotransformation fate in different redox conditions and activated sludge source. It should be noted that this classification is based only on the biotransformation fate and the degradation rates vary in each group.

\section{Group 1: Compounds that biotransformed under all three redox conditions and both sludge}

sources. Atenolol readily biotransformed under all three redox conditions in both treatment plants. The biotransformation rates of atenolol were highest under aerobic conditions in both the $\mathrm{OH}\left(3.58 \mathrm{~L} / \mathrm{g}_{\mathrm{vss}}\right.$-day) and NV (2.26 L/g $\mathrm{g}_{\mathrm{vss}}-$ day) activated sludge. The anoxic biotransformation rate of atenolol in $\mathrm{OH}\left(3.36 \mathrm{~L} / \mathrm{g}_{\mathrm{vss}}\right.$-day) was similar to the aerobic rate in $\mathrm{OH}$. Inyang et al. (2016) also observed the biotransformation of atenolol in activated sludge under three redox conditions in BNR treatment (aerobic $=5.28 \mathrm{~L} / \mathrm{g}_{\mathrm{TSS}}-\mathrm{day}$, anaerobic $=0.43 \mathrm{~L} / \mathrm{g}_{\mathrm{TSS}}$-day and anoxic $=1.7 \mathrm{~L} / \mathrm{g}_{\mathrm{TSS}}$-day), but their rates were higher than the $\mathrm{k}_{\mathrm{bio}}\left(\right.$ in $\mathrm{L} / \mathrm{g}_{\mathrm{TSS}-\text { day }}$ ) values seen here in both the treatment plants (Table1).

Trimethoprim biotransformed under all three redox condition in activated sludge collected from both treatment plants, but the biotransformation rates were slower than atenolol (TMP OH: aerobic $=0.14 \mathrm{~L} / \mathrm{g}_{\mathrm{vss}}-$ day, anaerobic $=0.24 \mathrm{~L} / \mathrm{g}_{\mathrm{vss}}-$ day, anoxic $=0.19 \mathrm{~L} / \mathrm{g}_{\mathrm{vss}}-$ day and TMP NV: aerobic $=0.75 \mathrm{~L} / \mathrm{g}_{\mathrm{vss}}-$ day, anaerobic $=0.33 \mathrm{~L} / \mathrm{g}_{\mathrm{vss}}-$ day, anoxic $=0.81 \mathrm{~L} / \mathrm{g}_{\mathrm{vss}}-$ day $)$. The biotransformation rates of trimethoprim in $\mathrm{NV}$ were greater than $\mathrm{OH}$ for all three redox conditions. Conflicting observations has been seen in the literature with studies reporting trimethoprim being recalcitrant or being biotransformed (Fernandez-Fontaina et al., 2016; Deng et al., 2016). Inyang et al. (2016) observed the biotransformation of trimethoprim only in aerobic and anoxic activated sludge with no biotransformation in anaerobic activated sludge. Saurez et al. (2010) studied the biotransformation of trimethoprim under nitrifying and denitrifying conditions and reported a biotransformation rate of $0.15 \mathrm{~L} / \mathrm{g}_{\mathrm{TSS}}$-day under aerobic 
nitrifying conditions, which is similar to the aerobic biotransformation rate for $\mathrm{OH}\left(0.11 \mathrm{~L} / \mathrm{g}_{\mathrm{TsS}}{ }^{-}\right.$ day), but they did not observe any biotransformation of trimethoprim in anoxic activated sludge.

Sulfamethoxazole biotransformed at rates similar to trimethoprim. The highest biotransformation rate for sulfamethoxazole was in $\mathrm{OH}$ aerobic activated sludge $\left(0.17 \mathrm{~L} / \mathrm{g}_{\mathrm{vss}}-\mathrm{d}\right)$ and the lowest was in the $\mathrm{OH}$ anaerobic activated sludge $\left(0.025 \mathrm{~L} / \mathrm{g}_{\mathrm{vss}}-\mathrm{d}\right)$. Plosz et al. (2010) reported both aerobic and anoxic biotransformation rates of $0.41 \mathrm{~L} / \mathrm{g}_{\mathrm{TSS}}$-day for sulfamethoxazole, which is greater than the rates normalized with TSS in this study.

Group 2: No biotransformation under any condition. Carbamazepine was recalcitrant to biotransformation in activated sludge from both sources under all three redox conditions. Others have also reported the recalcitrance of carbamazepine in aerobic activated sludge. (Jelic et al., 2011; Majewsky et al., 2011; Radjenovic et al., 2009; Salveson et al., 2012). However, Hai et al. (2011) observed an exceptionally high removal of carbamazepine (68\% removal) under near anoxic $(\mathrm{DO}=0.5 \mathrm{mg} / \mathrm{L})$ operational condition in a laboratory scale membrane bioreactor (MBR). The removal observed under aerobic condition (20\%) was also higher than those reported in the literature (Hai et al. 2011). They hypothesized that their MBR may harbor microbes that might degrade carbamazepine, but further microbial community analysis is needed to substantiate their hypothesis (Hai et al. 2011). 


\section{Group 3: Compounds whose biotransformation was dependent on the redox condition and the}

sludge source. In this group, there were three compounds, namely benzotriazole, DEET, and triclosan, that biotransformed under aerobic and anoxic conditions in $\mathrm{NV}$, but only under aerobic conditions for $\mathrm{OH}$. The aerobic biotransformation rate of benzotriazole was comparable ( 0.19 $\mathrm{L} / \mathrm{g}_{\mathrm{vss}}-\mathrm{d}$ in $\mathrm{OH}$ and $0.15 \mathrm{~L} / \mathrm{g}_{\mathrm{vss}}-\mathrm{d}$ in NV) in activated sludge from both treatment plants. Mazioti et al. (2015) reported biotransformation rates of benzotriazole under aerobic and anoxic conditions to be $0.38 \mathrm{~L} / \mathrm{g}_{\mathrm{TSS}}-\mathrm{d}$ and $0.24 \mathrm{~L} / \mathrm{g}_{\mathrm{TSS}}-\mathrm{d}$, respectively, at rates slightly higher than this study.

Triclosan had aerobic biotransformation rates of $0.49 \mathrm{~L} / \mathrm{g}_{\mathrm{TSS}}-\mathrm{d}$ in $\mathrm{OH}$ and $0.31 \mathrm{~L} / \mathrm{g}_{\mathrm{TSS}}-\mathrm{d}$ in NV activated sludge. Triclosan is well known to biodegrade under aerobic conditions (Inyang et al., 2016; McAvoy et al., 2002; Salveson et al. 2012). Inyang et al. (2016) reported significant removal of triclosan in batch degradation studies using anaerobic and anoxic activated sludge, but the mechanism was predominantly sorption. Similarly, Phan et al. (2016) attributed the anoxic removal of triclosan in a laboratory scale anoxic-aerobic membrane bioreactor to be mostly due to sorption on the biosolids. Chen et al. (2011) observed biodegradation of triclosan to methyl-triclosan in anoxic activated sludge, but they did not study the kinetics of the reaction. To our knowledge this is the first study to report an anoxic biotransformation rate for triclosan.

DEET biotransformed rapidly in $\mathrm{OH}$ aerobic activated sludge (5.43 $\left.\mathrm{L} / \mathrm{g}_{\mathrm{vss}}-\mathrm{d}\right)$, but no biotransformation was observed under anaerobic or anoxic conditions in $\mathrm{OH}$ activated sludge. In NV activated sludge, DEET biotransformed under aerobic and anoxic conditions, although the rate was much slower in anoxic activated sludge $\left(0.04 \mathrm{~L} / \mathrm{g}_{\mathrm{vss}}-\mathrm{d}\right)$. Inyang et al. (2016) observed the biotransformation of DEET only in aerobic activated sludge. 
The target compounds were also classified into rapid biotransformation rates $\left(\mathrm{k}_{\mathrm{bio}}>1 \mathrm{~L}_{\mathrm{v}_{\mathrm{vs}}}{ }^{-}\right.$ d), moderate biotransformation rates $\left(1 \mathrm{~L} / \mathrm{g}_{\mathrm{vss}}-\mathrm{d}>\mathrm{k}_{\mathrm{bio}}>0.1 \mathrm{~L} / \mathrm{g}_{\mathrm{vss}}-\mathrm{d}\right)$ and slow biotransformation rates $\left(0.1 \mathrm{~L} / \mathrm{g}_{\mathrm{vss}}-\mathrm{d}>\mathrm{k}_{\text {bio }}>0.01 \mathrm{~L} / \mathrm{g}_{\mathrm{vss}}-\mathrm{d}\right)$. DEET and atenolol were the only two compounds to biotransform rapidly. All of the other compounds biotransformed either moderately or slowly. All the anoxic and anaerobic biotransformation rates were either moderate or slow, except for atenolol that biotransformed rapidly in anoxic activated sludge from NV.

\subsubsection{Impact of Redox Condition on Biotransformation}

All of the compounds evaluated except carbamazepine biotransformed in aerobic activated sludge collected from both treatment plants. Compounds such as benzotriazole, DEET, and triclosan biotransformed only in aerobic activated sludge and not in anoxic or anaerobic activated sludge from $\mathrm{OH}$. Thus, aerobic redox conditions may be more favorable for metabolization of the target TOrCs due to maximum free energy available for substrate utilization (Inyang et al., 2016). Moreover, it has been shown that improvement in removal of TOrCs in wastewater treatment can be achieved under high DO conditions (Xue et al., 2010), nitrifying conditions where $\mathrm{NH}_{3}$ oxidation is catalyzed by ammonia monooxygenase (AMO) enzymes (Anderson et al., 2003; Joss et al., 2004; Li et al., 2011; Suarez et al., 2010; Phan et al., 2014) and the presence of archaea (Helbling et al., 2012). The AMO enzyme is known to catalyze the biotransformation of compounds like bisphenol A (Sun et al., 2012), synthetic and natural estrogens (Khunjar et al., 2011a), iopromide (Batt et al., 2006), and ibuprofen and naproxen (Fernandez-Fontaina et al., 2016). While the AMO enzyme has very low substrate

specificity (Rsche et al., 1991), its catalytic effect is highly dependent on the structure of the compound. For example, catalyzation by AMO is hampered by the presence of specific functionalities in the chemical structure like heterocyclic rings, aromatic rings, amide groups, 
and amine groups that occur in sulfamethoxazole, trimethoprim, and carbamazepine (Boethling et al. 1994, Keener and Arp 1994, Fernandez-Fontaina et al. 2016). Hence, action of the AMO enzyme on any observed biotransformation of these compounds is highly unlikely. Other ammonia oxidizing enzymes (Helbling et al., 2010; Men et al., 2017) or heterotrophic bacteria (Fernandez Fontaina et al., 2016; Khunjar et al., 2011a) may be responsible for the biotransformation of TOrCs in aerobic activated sludge. For example, atenolol with a primary amide is known to undergo enzymatic hydrolysis to atenololic acid under aerobic conditions by amide hydrolyzing enzymes (e.g., amidase) that are abundant in activated sludge microbial communities (Radjenovic et al., 2008; Helbling et al., 2010). Also, hydrolysis does not require oxygen in the biochemical reactions (Stadler and Love, 2016) and thus enzymatic hydrolysis may explain the anoxic and anaerobic biotransformation of atenolol in this study. This finding is also supported by the methanol inhibition test of atenolol whereby the enzymes responsible for hydrolysis transformation were denatured (Supplementary Material, Figure S-7).

There are instances where the biotransformation rate is comparable or even greater in anoxic activated sludge than aerobic activated sludge (Table 1: ATN and TMP in OH, BTA and TMP in $\mathrm{NV}$ ). Thus, the absence of oxygen does not necessarily limit biotransformation of TOrCs in activated sludge where other electron acceptors such as nitrate are present. In BNR treatment plants with $\mathrm{A}^{2} \mathrm{O}$ design, the return activated sludge and the internal recycle activated sludge circulates biomass from aerobic conditions to anaerobic and anoxic conditions, respectively (Figure 1). This recirculation creates a unique environment where facultative heterotrophs and their enzyme pools are shared between redox conditions enabling biotransformation even under low DO conditions (Gomez-Silvan et al., 2014; Phan et al., 2016). This transfer of enzymes may explain the biotransformation of atenolol, sulfamethoxazole, and trimethoprim under all three 
redox conditions from both the treatment plants. Several heterotrophic strains of bacteria like Pseudomonas sp., Rhodococcus sp., Microbacterium sp., Rhodococcus sp., Achromobacter sp., Ralstonia sp., Tsukumurella sp., Brevundimonas sp., and Variovorax sp. have been identified from aerobic activated sludge that can biotransform or even mineralize sulfamethoxazole (Larcher and Yargeau 2011; Bouju et al. 2012; Herzog et al. 2013). Ogunlaja and Parker (2018) studied the removal of trimethoprim in UCT-BNR design and concluded that ammonia oxidizing bacteria, heterotrophs and PAOs work collaboratively in the overall removal of trimethoprim. But their individual contribution is at different proportions in the order of heterotrophs > ammonia oxidizers $>$ PAOs in aerobic activated sludge and heterotrophs $>$ PAOs in anoxic and anaerobic activated sludge (Ogunlaja and Parker, 2018). Phan et al. (2016) studied the bacterial communities grown in an anoxic-aerobic MBR and observed a high similarity in structural and phylogenetic relationships because of the recycling of aerobic activated sludge. A better understanding of the microbial communities may help explain the anoxic biotransformation of Group 3 compounds (benzotriazole, DEET and triclosan) in NV activated sludge. However, anoxic activated sludge from $\mathrm{OH}$ was not able to biotransform these compounds. This lack of transformation could be because the facultative microbes responsible for the biotransformation of these compounds in NV activated sludge may not be present in the $\mathrm{OH}$ activated sludge. Metagenomic studies on the microbial community for each redox condition at both of the treatment plants would be required to confirm the absence or presence of biotransforming bacterial communities.

\subsubsection{Impact of Solid Retention Time on Biotransformation}

The average retention time of the microbes held in the system dictates the microbial community structure of activated sludge. Changes in SRT have been shown to shift the 
community structure by increasing or reducing the abundance of a taxa (Vuono et al., 2015; Phan et al., 2016). If the SRT is not sufficiently long, slow growing microbes that can potentially degrade a particular compound could be washed out of the system. A positive correlation between longer SRT and better removal of TOrCs has been reported for: (a) bisphenol-A, ibuprofen, benzafibrate, and natural estrogens (Clara et al. 2005); (b) fluoxetine, naproxen, citalopram, natural and synthetic estrogens (Suarez et al. 2010), (c) trimethoprim (Gobel et al. 2007); and (d) atenolol, DEET and sulfamethoxazole (Gerrity et al., 2013). In this study, atenolol and DEET showed better biotransformation performance under the higher SRT (OH SRT $=23$ day). The biotransformation rate of DEET in $\mathrm{OH}$ aerobic activated sludge $\left(5.43 \mathrm{~L} / \mathrm{g}_{\mathrm{vss}}\right.$-day) was more than five times greater than the rate in $\mathrm{NV}$ aerobic activated sludge $\left(0.87 \mathrm{~L} / \mathrm{g}_{\mathrm{vss}}\right.$-day). Similarly, the biotransformation rates of atenolol under all three redox conditions were greater in OH when compared to NV (Table 1).

Better degradation with higher SRT was not consistent for all of the TOrCs studied. For example, a higher biotransformation rate occurred with a lower SRT (NV SRT $=8$ days) for trimethoprim (Table 1). Since the activated sludge was procured from a BNR treatment plant with biological phosphorus removal, one could expect an abundance in phosphorus accumulating organisms (PAO) in the system that would be favorable under lower SRT conditions. PAOs belonging to bacteria taxa Rhodocyclales and Pseudomonadales have been shown to have greater abundance following a decrease in SRT (Vuono et al., 2015; Phan et al., 2016). Thus, the biotransformation of trimethoprim at NV may be related to PAOs that thrive under lower SRT conditions. However, this relationship would need to be verified with detailed microbial community structure analysis. The SRT did not affect the biotransformation rates of benzotriazole, sulfamethoxazole, and triclosan with rates for a given redox condition comparable 
between the two BNR treatment plants. This non-effect of a higher SRT on the biotransformation of benzotriazole, sulfamethoxazole, and triclosan may be due to: (a) slower growing microorganisms are not responsible for their biotransformation, (b) shorter SRT is sufficient to support the microbes responsible for biotransforming these compounds; or (c) the difference in SRT between the treatment plants (NV 8 days and $\mathrm{OH} 23$ days) is not significant enough to observe any difference.

\subsection{Sorption distribution coefficient}

Five compounds (TCS, SMX, CBZ, DEET and BTA) were chosen for determining their sorption-distribution coefficient (Table 2). These compounds were classified on their average log $\mathrm{K}_{\mathrm{d}}$ values as highly sorptive $\left(\log \mathrm{K}_{\mathrm{d}}>3\right)$, moderately sorptive $\left(2<\log \mathrm{K}_{\mathrm{d}}<3\right)$, and lowly sorptive $\left(\log \mathrm{K}_{\mathrm{d}}<2\right)$.

Highly sorptive $\left(\log K_{d}>3\right):$ Triclosan was the only highly sorptive compound in this study with $\mathrm{K}_{\mathrm{d}}$ values ranging from 6,516 to $10,541 \mathrm{~L} / \mathrm{kg}-\mathrm{MLSS}\left(\log \mathrm{K}_{\mathrm{d}}=3.81-4.02\right)$. Hyland et al. (2012) reported $\log \mathrm{K}_{\mathrm{d}}$ values for triclosan to range between 3.28 and 3.98 for aerobic activated sludge, which are slightly lower than the values found in this study. 
Table 2. Sorption-distribution coefficients (at $\mathrm{pH}=7.5$ ) in aerobic, anoxic, and anaerobic activated sludge for two BNR treatment plants $(\mathrm{OH}$ and $\mathrm{NV}) . \mathrm{K}_{\mathrm{d} \pm 95 \%} \mathrm{CI}$. Literature measured $\mathrm{K}_{\mathrm{d}}$ values are also provided for comparison.

\begin{tabular}{|c|c|c|c|c|c|c|c|c|c|c|c|c|c|c|c|c|}
\hline \multirow{3}{*}{$\begin{array}{l}\text { Sorption } \\
\text { Capacity }\end{array}$} & \multirow{3}{*}{ TOrC } & \multicolumn{6}{|c|}{ OH $($ SRT $=23$ days $)$} & \multicolumn{6}{|c|}{ NV (SRT = 8 days) } & \multicolumn{3}{|c|}{ Literature $K_{d}$ in $L / k g$} \\
\hline & & \multicolumn{2}{|c|}{ Anaerobic } & \multicolumn{2}{|c|}{ Anoxic } & \multicolumn{2}{|c|}{ Aerobic } & \multicolumn{2}{|c|}{ Anaerobic } & \multicolumn{2}{|c|}{ Anoxic } & \multicolumn{2}{|c|}{ Aerobic } & \multirow{2}{*}{ Anaerobic } & \multirow{2}{*}{ Anoxic } & \multirow{2}{*}{ Aerobic } \\
\hline & & $\mathrm{L} / \mathrm{kg}$ & $\log K_{d}$ & $\mathrm{~L} / \mathrm{kg}$ & $\log K_{d}$ & $\mathrm{~L} / \mathrm{kg}$ & $\log K_{d}$ & $\mathrm{~L} / \mathrm{kg}$ & $\log K_{d}$ & $\mathrm{~L} / \mathrm{kg}$ & $\log K_{d}$ & $\mathrm{~L} / \mathrm{kg}$ & $\log K_{d}$ & & & \\
\hline High & TCS & $\begin{array}{r}8058 \\
\pm \\
2107\end{array}$ & 3.91 & $\begin{array}{r}8828 \\
\pm \\
1895\end{array}$ & 3.95 & $\begin{array}{r}6515 \\
\pm \\
2115\end{array}$ & 3.81 & $\begin{array}{r}9351 \\
\pm \\
1524\end{array}$ & 3.97 & $\begin{array}{r}10541 \\
\pm 1309\end{array}$ & 4.02 & $\begin{array}{r}9053 \\
\pm \\
844\end{array}$ & 3.96 & NA & NA & $1905-9550^{\mathrm{a}}$ \\
\hline \multirow{3}{*}{ Moderate } & SMX & $\begin{array}{l}241 \\
\pm 20\end{array}$ & 2.38 & $\begin{array}{r}189 \\
\pm 14\end{array}$ & 2.28 & $\begin{array}{l}26^{*} \\
\pm 4\end{array}$ & $1.42 *$ & $\begin{array}{l}104 * \\
\pm 20\end{array}$ & $2.02 *$ & $\begin{array}{l}162 \\
\pm 25\end{array}$ & 2.21 & $\begin{array}{r}188 \\
\pm 14\end{array}$ & 2.27 & NA & NA & $\begin{array}{l}269^{\mathrm{a}}, 11^{\mathrm{b}}, 40-50^{\mathrm{c}} \\
<30^{\mathrm{d}}, 77^{\mathrm{e}}, 17-18^{\mathrm{l}}\end{array}$ \\
\hline & $\mathrm{CBZ}$ & $\begin{array}{l}302 \\
\pm 22\end{array}$ & 2.48 & $\begin{array}{r}208 \\
\pm 10\end{array}$ & 2.32 & $\begin{array}{l}68 * \\
\pm 5\end{array}$ & $1.83 *$ & $\begin{array}{l}134 \\
\pm 8\end{array}$ & 2.13 & $\begin{array}{r}251 \\
\pm 21\end{array}$ & 2.40 & $\begin{array}{r}250 \\
\pm 28\end{array}$ & 2.40 & $3870^{\mathrm{i}}$ & $6550^{\mathrm{i}}$ & $\begin{array}{c}86^{\mathrm{a}},<1^{\mathrm{b}},<8^{\mathrm{c}}, 36- \\
65^{\mathrm{d}}, 135^{\mathrm{e}}, 1^{\mathrm{f}}, 17^{\mathrm{g}}, \\
28-66^{\mathrm{h}}, 940^{\mathrm{i}}, 52-76^{\mathrm{l}}\end{array}$ \\
\hline & DEET & $\begin{array}{r}224 \\
\pm 55\end{array}$ & 2.35 & $\begin{array}{r}149 \\
\pm 14\end{array}$ & 2.17 & $\begin{array}{r}62 \\
\pm 12\end{array}$ & 1.79 & $\begin{array}{r}146 \\
\pm 11\end{array}$ & 2.17 & NA & NA & NA & NA & $1550^{\mathrm{i}}$ & $1950^{\mathrm{i}}$ & $\begin{array}{c}81^{\mathrm{a}},<31-<100^{\mathrm{d}} \\
850^{\mathrm{i}}\end{array}$ \\
\hline Low & BTA & $\begin{array}{r}59 \\
\pm 5.2\end{array}$ & 1.77 & $\begin{array}{l}86 \\
\pm 11\end{array}$ & 1.94 & $\begin{array}{l}14 * \\
\pm 8\end{array}$ & $1.17 *$ & $\begin{array}{r}123 \\
\pm 32\end{array}$ & 2.09 & $71 \pm 7$ & 1.86 & $\begin{array}{r}58 \\
\pm 20\end{array}$ & 1.76 & NA & NA & $220^{\mathrm{j}}, 133^{\mathrm{k}}$ \\
\hline \multicolumn{17}{|c|}{$\begin{array}{l}\text { *indicates the } \mathrm{K}_{\mathrm{d}} \text { values were determined from single p } \\
\text { (2009); d) Stevens-Garmon et al. (2011); e) Radjenovic } \\
\text { (2015); k) Stasinakis et al. (2013); 1) Yan et al. (2014) }\end{array}$} \\
\hline
\end{tabular}


Moderately sorptive $\left(2<\log K_{d}<3\right)$ : Sulfamethoxazole, carbamazepine, and DEET were classified as moderately sorptive. The $K_{d}$ values for sulfamethoxazole ranged from 188 to 241 L/kg-MLSS $\left(\log \mathrm{K}_{\mathrm{d}}=2.27-2.38\right)$, which were similar to the value $269 \mathrm{~L} / \mathrm{kg}-\mathrm{MLSS}$ reported by Hyland et al. (2012) and the value 256 \pm 169 L/kg-MLSS reported by Gobel et al. (2005). The $\mathrm{K}_{\mathrm{d}}$ values for carbamazepine ranged from 134 to $302 \mathrm{~L} / \mathrm{kg}-\mathrm{MLSS}\left(\log \mathrm{K}_{\mathrm{d}}=2.13-2.48\right)$ with an average $\log K_{d}$ value for all redox conditions and treatment plants of $2.34 \pm 0.13(n=5)$. Other studies reported much lower sorption distribution coefficients $(<86 \mathrm{~L} / \mathrm{kg}-\mathrm{MLSS})$ for carbamazepine (Fernandez-Fonataina et al. 2013; Abegglen et al. 2005; Ternes et al., 2004; Urase and Kikuta, 2005; Stevens-Garmon et al., 2011; Hyland et al., 2012; and Wick et al. 2009). Radjenovic et al. (2009) reported a $\mathrm{K}_{\mathrm{d}}$ value of $135 \mathrm{~L} / \mathrm{kg}-\mathrm{MLSS}$ for carbamazepine, which is similar to the values reported herein. The $\mathrm{K}_{\mathrm{d}}$ values for DEET ranged from 62 to 224 L/kg-MLSS $\left(\log \mathrm{K}_{\mathrm{d}}=1.79-2.35\right)$. The average $\log \mathrm{K}_{\mathrm{d}}$ value for all redox conditions and treatment plants was $2.12 \pm 0.24(\mathrm{n}=4)$. Xue et al. (2010) reported sorption distribution coefficients $\left(\log \mathrm{K}_{\mathrm{d}}\right.$ ) for DEET of 2.93 (aerobic), 3.29 (anoxic), and 3.18 (anaerobic), which are slightly higher than the values found in the current study.

Lowly sorptive $\left(\log K_{d}<2\right)$ : The $\mathrm{K}_{\mathrm{d}}$ values for benzotriazole ranged from 86 to $123 \mathrm{~L} / \mathrm{kg}$-MLSS $\left(\log K_{d}=1.94-2.09\right)$ with an average $\log K_{d}$ value for all redox conditions and treatment plants of $1.88 \pm 0.14(\mathrm{n}=5)$. Mazioti et al. (2015) and Stasinakis et al. (2013) reported higher sorption distribution coefficients for benzotriazole of $220 \mathrm{~L} / \mathrm{kg}-\mathrm{MLSS}$ and $133 \mathrm{~L} / \mathrm{kg}-\mathrm{MLSS}$, respectively.

\subsubsection{Impact of Redox Condition and SRT}

It has been established that there are significant differences in sorption affinity among primary, activated sludge and digested sludge because of the variation in their composition 
(Berthod et al., 2016; Horsing et al., 2011). However, it is not clear if any differences occur in the sorption behavior of TOrCs due to different redox conditions of activated sludge. Due to internal recycle rates and different redox conditions within a BNR treatment system, there are changes in the microbial composition of the sludge (Vuono et al., 2015) that could affect the sorption capacity.

Regression plots of $\log \mathrm{K}_{\mathrm{d}}$ values for the different redox conditions and two treatment plants are shown in Figure 2. Variability in $\log \mathrm{K}_{\mathrm{d}}$ values of low to moderately sorptive compounds (BTA, CBZ, DEET and SMX) were more than the highly sorptive compound triclosan (Figure 2). All four plots showed high correlation $\left(\mathrm{R}^{2}>0.8\right)$ between redox conditions. The highest correlation was between anoxic and anaerobic activated sludge $\left(\mathrm{R}^{2}=0.95\right)$ with a slope coefficient close to 1 . Horsing et al. (2011) found similar $\log \mathrm{K}_{\mathrm{d}}$ values for sulfamethoxazole in activated sludge with SRTs of 3 days and 10 days. Hyland et al. (2012) did not observe a significant effect of SRT on the sorption capacity for both ionic and neutral TOrCs. They also characterized the aerobic sludge solids used in their $\mathrm{K}_{\mathrm{d}}$ estimations and found no significant change in the cation exchange capacity or the organic carbon fraction among six different activated sludge sources. Other sludge characteristics like particle size distribution, zeta potential, and availability of extracellular polymeric substances (EPS) have been shown to influence the sorption of TOrCs like trimethoprim (Khunjar and Love, 2011b). Further studies are required to explore how sludge morphology varies among redox conditions, SRT, and treatment plant configurations and how these factors impact the sorption process. 


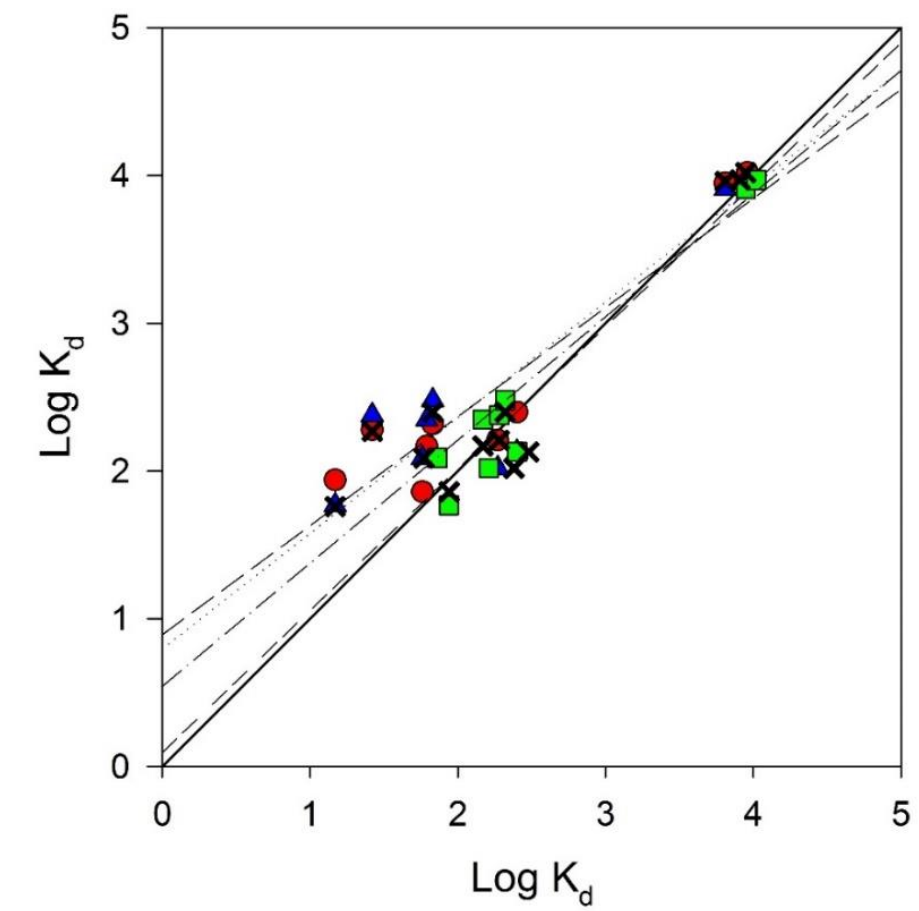

Aerobic vs Anoxic Plot

Aerobic vs Anoxic Regression $\quad----\quad$ Anoxic Vs Anaerobic Regression

Aerobic vs Anaerobic Plot $\quad$ X OH vs NV Plot

Aerobic vs Anaerobic Regression - - - - OH vs NV Regression

Figure 2 - Plots of $\log K_{d}$ values between Aerobic vs Anoxic (Anoxic $\log K_{d}=0.78 \times$ Aerobic $\left.\log K_{d}+0.79, R^{2}=0.89, n=9\right)$, Aerobic vs Anaerobic (Anaerobic $\log K_{d}=$ $0.73 \times$ Aerobic $\log K_{d}+0.89, R^{2}=0.82, n=9$ ), Anoxic vs Anaerobic (Anaerobic $\log$ $K_{d}=0.96 \times$ Anoxic $\left.\log K_{d}+0.09, R^{2}=0.95, n=9\right)$ and $\mathrm{OH}$ vs NV $\left(N V \log K_{d}=0.83 \times\right.$ OH $\left.\log K_{d}+0.54, R^{2}=0.85, n=13\right)$. Solid line indicates 1:1 $(y=x)$ plot.

\subsubsection{Hydrophobicity as a predictor for sorption-distribution coefficient}

Several studies have proposed that sorption of TOrCs to sludge solids is a function of their hydrophobicity and empirical models based on the octanol-water partition coefficient $\left(\mathrm{K}_{\mathrm{ow}}\right)$ have been developed to predict the sorption distribution coefficient. These estimations take the general form of $\log \mathrm{K}_{\mathrm{d}}=\mathrm{a} \times \log \mathrm{K}_{\mathrm{ow}}+\mathrm{b}$, where $\mathrm{a}$ and $\mathrm{b}$ are empirical constants determined from 
an experimental dataset. Several models derived from experiment data using activated sludge solids and their predictions are provided in Table 3. Mattermuller et al. (1980) consistently under predicted the $\log \mathrm{K}_{\mathrm{d}}$ value. Stevens-Garmon et al. (2011) and Hyland et al. (2012) proposed models to predict the organic-carbon distribution coefficient $\left(\mathrm{K}_{\mathrm{oc}}\right)$ for neutral compounds such as triclosan, DEET, and carbamazepine. While the model by Stevens-Garmon et al. (2011) underpredicts the sorption of these compounds, the model by Hyland et al. (2012) shows good prediction $(\mathrm{RMSE}=0.16)$ for triclosan and carbamazepine. The model by Jacobson et al. (1993) $(a=0.58, b=1.14)$ showed very good predictions for most compounds with RMSE $=0.25$. It is interesting to note that empirical constants and predictions from Jacobsen et al. (1993), where the compounds studied were chlorinated phenols and chlorinated benzene, were similar to the constants using data from this study (measured $\log \mathrm{K}_{\mathrm{d}} \mathrm{vs} \log \mathrm{K}_{\mathrm{ow}}, \mathrm{a}=0.54, \mathrm{~b}=1.18$ ). Given the differences in the suite of chemicals studied by Jacobsen et al. (1993) that had $\log \mathrm{K}_{\mathrm{ow}}>3.5$ and the compounds evaluated in this study with $\log \mathrm{K}_{\mathrm{ow}}$ values ranging from 0.89 to 4.76 , the similarity between the two equations could be entirely coincidental. While these single parameter models provide a plausible estimate of sorption distribution coefficient, it has been proposed that multi-parameter models with descriptors of the chemical and the solid phase might provide more reliable predictions (Horsing et al., 2011; Sathyamoorthy et al., 2013). 
Table 3. Comparison of measured sorption-distribution coefficients (mean $\log K_{d} \pm S D$ ) with predicted values using empirical models based on hydrophobicity.

\begin{tabular}{|c|c|c|c|c|c|c|c|}
\hline \multirow[b]{2}{*}{ TOrC } & \multirow[b]{2}{*}{$\begin{array}{l}\log \\
\mathbf{K}_{\text {ow }}\end{array}$} & \multirow[b]{2}{*}{$\begin{array}{c}\text { Measured } \\
\log K_{d}\end{array}$} & \multicolumn{5}{|c|}{ Predicted $\log K_{d}$} \\
\hline & & & $\begin{array}{l}\text { From } \\
\text { this } \\
\text { study }\end{array}$ & $\begin{array}{c}\text { Jacobsen } \\
\text { et al. } \\
(\mathbf{1 9 9 3 )}\end{array}$ & $\begin{array}{l}\text { Mattermuller } \\
\text { et al.(1980) }\end{array}$ & $\begin{array}{c}\text { Stevens- } \\
\text { Garmon et } \\
\text { al. (2011) }\end{array}$ & $\begin{array}{l}\text { Hyland et } \\
\text { al. (2012) }\end{array}$ \\
\hline TCS & 4.76 & $3.94 \pm 0.1$ & 3.75 & 3.90 & 3.58 & 3.20 & 3.87 \\
\hline $\mathrm{CBZ}$ & 2.45 & $2.26 \pm 0.2$ & 2.50 & 2.56 & 2.03 & 1.81 & 2.05 \\
\hline DEET & 2.18 & $2.12 \pm 0.2$ & 2.36 & 2.40 & 1.85 & 1.65 & 1.84 \\
\hline BTA & 1.23 & $1.77 \pm 0.3$ & 1.84 & 1.85 & 1.21 & - & - \\
\hline SMX & 0.89 & $2.04 \pm 0.4$ & 1.66 & 1.66 & 0.99 & - & - \\
\hline \multicolumn{3}{|c|}{ Root Mean Squared Error } & 0.24 & 0.26 & 0.57 & 0.43 & 0.16 \\
\hline \multicolumn{8}{|c|}{$\begin{array}{l}\text { Correlation from this study: } \log K_{d}=0.53 \times \log K_{o w}+1.18 \\
\text { Jacobsen et al. (1993): } \log K_{d}=0.58 \times \log K_{o w}+1.14 \\
\text { Stevens-Garmon et al. }(2011): \text { For } \log \mathrm{K}_{\mathrm{ow}}<2, \log K_{o c}=0.6 \times \log K_{o w}+0.69 \\
\text { Hyland et al. (2012): For } \log \mathrm{K}_{\mathrm{ow}}<2, \log K_{o c}=0.79 \times \log K_{o w}+0.47 \\
\mathrm{~K}_{\mathrm{d}=} \mathrm{K}_{\mathrm{oc}} \times \mathrm{f}_{\mathrm{oc}} \\
\mathrm{K}_{\mathrm{oc}}-\text { Organic-carbon partition coefficient }\end{array}$} \\
\hline
\end{tabular}

\subsection{Uncertainties in Parameter Estimation}

There are several factors that may contribute to uncertainty in the measurement of biotransformation rates. For example, the biotransformation of Group 3 compounds in this study occurred only under anoxic conditions. The difference in design and operational conditions renders each treatment plant with different biotransformation potential. The concentration of the target compound being spiked may also be different from one study to another, which can result in variability of the results. Some experimental procedures involve synthetic wastewater (Joss et al., 2006; Pomies et al., 2014) that could effectively change the mode of metabolism and even the biotransformation pathway (Muller et al., 2013). 
One source of uncertainty with the sorption-distribution coefficient estimations could be from differences in the sludge handling procedure. In particular, techniques of inactivation may vary among studies such as the addition of a chemical biocide (Hyland et al., 2012; Wick et al., 2009), freeze drying and heat inactivation (Sevens-Garmon et al., 2011; Mazioti et al., 2015), and use of argon gas (Ternes et al., 2004). Other experiments avoided procedures to limit biotransformation during the sorption experiment and used a two phase models to predict the sorption-distribution coefficient through curve fitting (Xue et al., 2010), which may not be accurate for slowly sorbing compounds since instantaneous sorption equilibrium is assumed. On comparison of the $\mathrm{K}_{\mathrm{d}}$ values for carbamazepine and DEET between Xue et al. (2010) and several others (Table 2), their model overestimated the measured $\mathrm{K}_{\mathrm{d}}$ values in this study. Thus, these factors of uncertainties should be carefully considered before adopting the fate parameters from model predictions.

\section{Conclusion}

This study determined biotransformation rates and sorption-distribution coefficients for select TOrCs in activated sludge from three different redox conditions in two BNR treatment plants configured in $\mathrm{A}^{2} \mathrm{O}$ process design. The biotransformation rates $\left(\mathrm{k}_{\mathrm{bio}}\right)$ were influenced by redox condition and solid retention time of the treatment plants as each treatment plant is unique in terms of its biological composition. A key finding was that a longer SRT may not necessarily mean better biotransformation if relevant microorganisms are not present (triclosan, DEET and benzotriazole) or if the structure of the compound is highly stable (carbamazepine). For compounds amenable to biotransformation by facultative heterotrophs, BNR treatment may be advantageous for their biotransformation (atenolol, trimethoprim and sulfamethoxazole) because the microbes responsible for degradation are circulated among the three redox zones (anaerobic, 
anoxic and aerobic). This study has also identified areas of future study using metagenomics techniques to better understand the biotransformation behavior of TOrCs in activated sludge from different redox conditions and SRTs.

There were high correlations between the sorption-distribution coefficients under different redox conditions, with the highest correlation seen between anaerobic and anoxic activated sludge. The impact of redox condition and SRT on the sorption distribution coefficient of the target TOrCs with activated sludge were compound specific. While the parameters measured in this study can be used as inputs to predictive BNR treatment models for estimating effluent concentrations, the biotransformation rates should be used with caution because of uncertainties associated with different activated sludge sources. The sorption-distribution coefficients do not vary much between activated sludge sources or among redox conditions, so their use in predictive models would have less uncertainty (particularly for the highly sorptive compounds). 


\section{Acknowledgement}

This research was funded by Water Environment and Reuse Foundation (Project \# U2R13). The authors would like to acknowledge support from the Southern Nevada Water Authority: Janie Zeigler-Holady and Brittney Stipanov for their assistance with the analysis of TOrCs in the biotransformation experiments, Mandu Inyang, Mac Gifford, Erica Marti, Marco Velarde and Assumption Grimaldi for their assistance in collecting the activated sludge samples; and David Rexing and Jenifer Fuel for administrative support. The authors also thank Zhiqiang Wang at the University of Cincinnati for his assistance with TOrCs analysis in the sorption study. The authors would also like to thank the wastewater treatment plant personnel at both $\mathrm{OH}$ and $\mathrm{NV}$ for their sampling efforts and for providing operational data at the time of sampling. 


\section{References}

Abegglen, C., Joss, A., McArdell, C. S., Fink, G., Schlüsener, M. P., Ternes, T. A., Siegrist, H. 2009. The fate of selected micropollutants in a single-house MBR. Water research 43 (7), 2036-2046.

Andersen, H., Siegrist, H., Halling-Sørensen, B., Ternes, T. A. 2003. Fate of Estrogens in a Municipal Sewage Treatment Plant. Environmental Science and Technology 37 (18), 40214026.

Batt, A. L., Kim, S., Aga, D. S. 2006. Enhanced biodegradation of lopromide and trimethoprim in nitrifying activated sludge. Environmental Science and Technology 40 (23), 7367-7373.

Behera, S. K., Kim, H. W., Oh, J., Park, H. 2011. Occurrence and removal of antibiotics, hormones and several other pharmaceuticals in wastewater treatment plants of the largest industrial city of Korea. Science of The Total Environment 409 (20), 4351-4360.

Berthod, L., Roberts, G., Sharpe, A., Whitley, D. C., Greenwood, R., Mills, G. A. 2016. Effect of sewage sludge type on the partition behavior of pharmaceuticals: A meta-analysis. Environmental Science: Water Research \& Technology 2, 154-163.

Boethling, R. S., Howard, P. H., Meylan, W., Stiteler, W., Beauman, J., Tirado, N. 1994. Groupcontribution method for predicting probability and rate of aerobic biodegradation. Environmental Science and Technology 28 (3), 459-465. 
Bouju, H., Ricken, B., Beffa, T., Corvini, P. F., Kolvenbach, B. A. 2012. Isolation of bacterial strains capable of sulfamethoxazole mineralization from an acclimated membrane bioreactor. Applied and Environmental Microbiology 78 (1), 277-279.

Cancilla, D. A., Holtkamp, A., Matassa, L., Fang, X. 1997. Isolation and characterization of Microtox ${ }^{\circledR}$-active components from aircraft de-icing/anti-icing fluids. Environmental Toxicology and Chemistry 16 (3), 430-434.

Chen, X., Nielsen, J. L., Furgal, K., Liu, Y., Lolas, I. B., Bester, K. 2011. Biodegradation of triclosan and formation of methyl-triclosan in activated sludge under aerobic conditions. Chemosphere 84 (4), 452-456.

Clara, M., Kreuzinger, N., Strenn, B., Gans, O., Kroiss, H. 2005. The solids retention time-a suitable design parameter to evaluate the capacity of wastewater treatment plants to remove micropollutants. Water research 39 (1), 97-106.

Clouzot, L., Choubert, J. M., Cloutier, F., Goel, R., Love, N. G., Melcer, H., Ort, C., Patureau, D., Plosz, B. G., Pomiès, M., and Vanrolleghem, P. A. 2013. Perspectives on modelling micropollutants in wastewater treatment plants. Water Science \& Technology 68 (2), 448-461. 
Deng, Y., Li, B., Yu, K., Zhang, T. 2016. Biotransformation and adsorption of pharmaceutical and personal care products by activated sludge after correcting matrix effects. Science of The Total Environment 544 (Supplement C), 980-986.

Diamond, J., Thornton, K., Munkittuck, K., Kidd, K., Bartell, S., Kapo, K. 2010. Diagnostic Tools to Evaluate Impacts of Trace Organic Compounds. Water Environment Research Foundation, Alexandria, VA: International Water Association. CEC5R08C.

Drewes, J. E., Shore, L. S. (2001) Concerns about Pharmaceuticals in Water Reuse, Groundwater Recharge, and Animal Waste. In: Daughton,C.G., Lepp C., L., J. (Ed.), Pharmaceuticals and Care Products in the Environment, American Chemical Society, Washington D. C., 206-228.

Eggen, R. I. L., Hollender, J., Joss, A., Schärer, M., Stamm, C. 2014. Reducing the discharge of micropollutants in the aquatic environment: The benefits of upgrading wastewater treatment plants. Environmental Science and Technology 48 (14), 7683- 7689.

Fernandez-Fontaina, E., Gomes, I. B., Aga, D. S., Omil, F., Lema, J. M., Carballa, M. 2016. Biotransformation of pharmaceuticals under nitrification, nitratation and heterotrophic conditions. Science of The Total Environment 541, 1439-1447.

Fernandez-Fontaina, E., Pinho, I., Carballa, M., Omil, F., Lema, J. M. 2013. Biodegradation kinetic constants and sorption coefficients of micropollutants in membrane bioreactors. Biodegradation 24 (2), 165-177. 
Gerrity, D., Holady, J. C., Mawhinney, D. B., Quiñones, O., Trenholm, R. A., Snyder, S. A. 2013. The Effects of Solids Retention Time in Full-Scale Activated Sludge Basins on Trace Organic Contaminant Concentrations. Water Environment Research 85 (8), 715-724.

Göbel, A., McArdell, C. S., Joss, A., Siegrist, H., Giger, W. 2007. Fate of sulfonamides, macrolides, and trimethoprim in different wastewater treatment technologies. Science of The Total Environment 372 (2-3), 361-371.

Gómez-Silván, C., Vílchez-Vargas, R., Arévalo, J., Gómez, M. A., González-López, J., Pieper, D. H., Rodelas, B. 2014. Quantitative response of nitrifying and denitrifying communities to environmental variables in a full-scale membrane bioreactor. Bioresource technology 169 , 126-133.

Hai, F. I., Li, X., Price, W. E., Nghiem, L. D. 2011. Removal of carbamazepine and sulfamethoxazole by MBR under anoxic and aerobic conditions. Bioresource Technology 102 (22), 10386-10390.

Harris, C. A., Routledge, E. J., Schaffner, C., Brian, J. V., Giger, W., Sumpter, J. P. 2007. Benzotriazole is anti-estrogenic in vitro but not in vivo. Environmental Toxicology and Chemistry 26 (11), 2367-2372. 
Helbling, D. E., Johnson, D. R., Honti, M., Fenner, K. 2012. Micropollutant biotransformation kinetics associate with WWTP process parameters and microbial community characteristics. Environmental Science and Technology 46 (19), 10579-10588.

Helbling, D. E., Hollender, J., Kohler, H. P., and Fenner, K. S. 2010. Structure-based interpretation of biotransformation pathways of amide-containing compounds in sludgeseeded bioreactors. Environmental Science and Technology. 2010, 44, Environmental Science and Technology 44 (17), 6628-6635.

Herzog, B., Lemmer, H., Horn, H., Müller, E. 2013. Characterization of pure cultures isolated from sulfamethoxazole-acclimated activated sludge with respect to taxonomic identification and sulfamethoxazole biodegradation potential. BMC Microbiology 13, 276. doi: $10.1186 / 1471-2180-13-276$.

Higgins C. P., Sharp, J. O., Sepulvado, J. G., Littrell, B., O’Connor, G. A., Snyder, E., McAvoy, D. C. 2010. State-of-the-Science Review of Occurrence and Physical, Chemical, and Biological Processes Affecting Biosolids-Borne Trace Organic Chemicals in Soil. Water Environment Research Foundation, Alexandria, VA: International Water Association. SRSK5T09.

Hörsing, M., Ledin, A., Grabic, R., Fick, J., Tysklind, M., Jansen, J. 1. C., Andersen, H. R. 2011. Determination of sorption of seventy-five pharmaceuticals in sewage sludge. Water research 45 (15), 4470-4482. 
Huntscha, S., Hofstetter, T. B., Schymanski, E. L., Spahr, S., and Hollender, J. 2014.

Biotransformation of Benzotriazoles: Insights from Transformation Product Identification and Compound-Specific Isotope Analysis. Environmental Science and Technology 48 (8), 44354443.

Hyland, K. C., Dickenson, E. R. V., Drewes, J. E., Higgins, C. P. 2012. Sorption of ionized and neutral emerging trace organic compounds onto activated sludge from different wastewater treatment configurations. Water Research 46 (6), 1958-1968.

Inyang, M., Flowers, R., McAvoy, D., Dickenson, E. 2016. Biotransformation of trace organic compounds by activated sludge from a biological nutrient removal treatment system. Bioresource technology 216, 778-784.

Isidori, M., Lavorgna, M., Nardelli, A., Pascarella, L., Parrella, A. 2005. Toxic and genotoxic evaluation of six antibiotics on non-target organisms. Science of the Total Environment 346 (1-3), 87-98.

Jacobsen, B. N., Nyholm, N., Pedersen, B. M., Poulsen, O., Østfeldt, P. 1993. Removal of organic micropollutants in laboratory activated sludge reactors under various operating conditions: sorption. Water Research 27 (10), 1505-1510. 
Jelic, A., Gros, M., Ginebreda, A., Cespedes-Sánchez, R., Ventura, F., Petrovic, M., Barcelo, D. 2011. Occurrence, partition and removal of pharmaceuticals in sewage water and sludge during wastewater treatment. Water research 45 (3), 1165-1176.

Joss, A., Andersen, H., Ternes, T., Richle, P. R., Siegrist, H. 2004. Removal of Estrogens in Municipal Wastewater Treatment under Aerobic and Anaerobic Conditions: Consequences for Plant Optimization. Environmental Science and Technology 38 (11), 3047-3055.

Keener, W.K., Arp, D.J. 1994. Transformations of aromatic compounds by Nitrosomonas europaea. Applied and Environmental Microbiology 60 (6), 1914-1920.

Kerr, K. M., Larson, R. J., McAvoy, D. C. 2000. Evaluation of an Inactivation Procedure for Determining the Sorption of Organic Compounds to Activated Sludge. Ecotoxicology and Environmental Safety 47 (3), 314-322.

Khunjar, W. O., MacKintosh, S. A., Skotnicka-Pitak, J., Baik, S., Aga, D. S., Love, N. G. 2011 a. Elucidating the relative roles of ammonia oxidizing and heterotrophic bacteria during the biotransformation of $17 \alpha$-ethinylestradiol and trimethoprim. Environmental Science and Technology 45 (8), 3605-3612.

Khunjar, W. O. and Love, N. G. 2011 b. Sorption of carbamazepine, 17 1 -ethinylestradiol, iopromide and trimethoprim to biomass involves interactions with exocellular polymeric substances. Chemosphere 82 (6), 917-922. 
Larcher, S. and Yargeau, V. 2011. Biodegradation of sulfamethoxazole by individual and mixed bacteria. Applied Microbiology and Biotechnology 91 (1), 211-218.

Li Y. M., Zeng Q. L., Yang S. J. 2011. Removal and fate of estrogens in an anaerobic-anoxicoxic activated sludge system. Water Science \& Technology 63 (1), 51-56.

Loos, R., Carvalho, R., António, D. C., Comero, S., Locoro, G., Tavazzi, S., Paracchini, B., Ghiani, M., Lettieri, T., Blaha, L., Jarosova, B., Voorspoels, S., Servaes, K., Haglund, P., Fick, J., Lindberg, R. H., Schwesig, D., Gawlik, B. M. 2013. EU-wide monitoring survey on emerging polar organic contaminants in wastewater treatment plant effluents. Water research 47 (17), 6475-6487.

Manikkam, M., Tracey, R., Guerrero-Bosagna, C., Skinner, M. K. 2012. Pesticide and insect repellent mixture (permethrin and DEET) induces epigenetic transgenerational inheritance of disease and sperm epimutations. Reproductive Toxicology 34 (4), 708-719.

Majewsky, M., Gallé, T., Yargeau, V., Fischer, K. 2011. Active heterotrophic biomass and sludge retention time (SRT) as determining factors for biodegradation kinetics of pharmaceuticals in activated sludge. Bioresource technology 102 (16), 7415-7421. 
Matter-Müller, C., Gujer, W., Giger, W., Stumm, W. (1981) Non-Biological Elimination Mechanisms in a Biological Sewage Treatment Plant. In: JENKINS, S.H. (Ed.), Water Pollution Research and Development, Pergamon, 299-314.

Mazioti, A. A., Stasinakis, A. S., Gatidou, G., Thomaidis, N. S., Andersen, H. R. 2015. Sorption and biodegradation of selected benzotriazoles and hydroxybenzothiazole in activated sludge and estimation of their fate during wastewater treatment. Chemosphere 131, 117-123.

McAvoy, D. C., Schecher, W. D., Rittman, B. E., Lee, K. C. 1999. ASTREAT: A Model for Calculating Chemical Loss within an Activated Sludge Treatment System. User's Manual. Version 1.0. The Procter \& Gamble Company.

McAvoy, D. C., Schatowitz, B., Jacob, M., Hauk, A., Eckhoff, W. S. 2002. Measurement of triclosan in wastewater treatment systems. Environmental Toxicology and Chemistry 21 (7), 1323-1329.

Melcer, H., Bell, J. P., Thompson, D. J., Yendt, C. M., Kemp, C.M., and Steel, P. 1994. Modeling Volatile Organic Contaminants' Fate in Wastewater Treatment Plants. Journal of Environmental Engineering 120 (3), 588-609.

Men, Y., Achermann, S., Helbling, D. E., Johnson, D. R., Fenner, K. 2017. Relative contribution of ammonia oxidizing bacteria and other members of nitrifying activated sludge communities to micropollutant biotransformation. Water research 109, 217-226. 
Ogunlaja, O. O. and Parker, W. J. 2018. Modeling the biotransformation of trimethoprim in biological nutrient removal system. Water Science and Technology 77 (6), In press.

Ogunlaja, O. O. and Parker, W. J. 2015. Assessment of the removal of estrogenicity in biological nutrient removal wastewater treatment processes. Science of the Total Environment 514, 202210.

Parker, W. J., Pileggi, V., Seto, P., Chen, X., Ogunlaja, M., Van Der Kraak, G., Parrott, J. 2014. Impact of activated sludge configuration and operating conditions on in vitro and in vivo responses and trace organic compound removal. Science of the Total Environment 490 (Supplement C), 360-369.

Phan, H. V., Hai, F. I., Zhang, R., Kang, J., Price, W. E., Nghiem, L. D. 2016. Bacterial community dynamics in an anoxic-aerobic membrane bioreactor - Impact on nutrient and trace organic contaminant removal. International Biodeterioration \& Biodegradation 109, 6172.

Phan, H. V., Hai, F. I., Kang, J., Dam, H. K., Zhang, R., Price, W. E., Broeckmann, A., Nghiem, L. D. 2014. Simultaneous nitrification/denitrification and trace organic contaminant (TrOC) removal by an anoxic-aerobic membrane bioreactor (MBR). Bioresource technology 165, 96104. 
Plosz, B. G., Leknes, H., Thomas, K. V. 2010. Impacts of Competitive Inhibition, Parent Compound Formation and Partitioning Behavior on the removal of Antibiotics in Municipal Wastewater Treatment. Environmental Science and Technology 44 (2), 734-742.

Pomiès, M., Choubert, J. -M., Wisniewski, C., Coquery, M. 2013. Modelling of micropollutant removal in biological wastewater treatments: A review. Science of the Total Environment $443,733-748$.

Radjenović, J., Petrović, M., Barceló, D. 2009. Fate and distribution of pharmaceuticals in wastewater and sewage sludge of the conventional activated sludge (CAS) and advanced membrane bioreactor (MBR) treatment. Water research 43 (3), 831-841.

Radjenović, J., Pérez, S., Petrović, M., Barceló, D. 2008. Identification and structural characterization of biodegradation products of atenolol and glibenclamide by liquid chromatography coupled to hybrid quadrupole time-of-flight and quadrupole ion trap mass spectrometry. Journal of Chromatography A 1210 (2), 142-153.

Rasche, M.E., Hyman, M.R., Arp, D.J. 1991. Factors limiting aliphatic chlorocarbon degradation by Nitrosomonas europaea: Cometabolic inactivation of ammonia monooxygenase and substrate specificity. Applied and Environmental Microbiology 57 (10), 2986-2994.

Rogers, H. R. 1996. Sources, behavior and fate of organic contaminants during sewage treatment and in sewage sludge. Science of the Total Environment 185 (1), 3-26. 
Rosal, R., Rodríguez, A., Perdigón-Melón, J. A., Petre, A., García-Calvo, E., Gómez, M. J., Agüera, A., Fernández-Alba, A. R. 2010. Occurrence of emerging pollutants in urban wastewater and their removal through biological treatment followed by ozonation. Water research $44(2), 578-588$.

Santos, J. L., Aparicio, I., Alonso, E. 2007. Occurrence and risk assessment of pharmaceutically active compounds in wastewater treatment plants. A case study: Seville city (Spain). Environment international 33 (4), 596-601.

Salveson, A., Rauch-Williams, T., Dickenson, E. R. V., Drewes, J. E., Drury, D., McAvoy, D. C., Snyder, S. 2012. Trace Organic Compound Removal during Wastewater Treatment Categorizing Wastewater Treatment Processes by their Efficacy in Reduction of a Suite of Indicator TOrC. Water Environment Research Foundation, Alexandria, VA. CEC4R08.

Sathyamoorthy, S. , Ramsburg, C.A. Assessment of quantitative structural property relationships for prediction of pharmaceutical sorption during biological wastewater treatment. Chemosphere, 92 (2013), pp. 639-646

Stadler, L. B. and Love, N. G. 2016. Impact of microbial physiology and microbial community structure on pharmaceutical fate driven by dissolved oxygen concentration in nitrifying bioreactors. Water research 104, 189-199. 
Stasinakis, A. S., Thomaidis, N. S., Arvaniti, O. S., Asimakopoulos, A. G., Samaras, V. G., Ajibola, A., Mamais, D., Lekkas, T. D. 2013. Contribution of primary and secondary treatment on the removal of benzothiazoles, benzotriazoles, endocrine disruptors, pharmaceuticals and perfluorinated compounds in a sewage treatment plant. Science of the Total Environment 463-464 (Supplement C), 1067-1075.

Stevens-Garmon, J., Drewes, J. E., Khan, S. J., McDonald, J. A., Dickenson, E. R. V. 2011. Sorption of emerging trace organic compounds onto wastewater sludge solids. Water Research 45 (11), 3417-3426.

Struijs, J., van de Meent, D., Schowanek, D., Buchholz, H., Patoux, R., Wolf, T., Austin, T., Tolls, J., van Leeuwen, K., Galay-Burgos, M. 2016. Adapting SimpleTreat for simulating behaviour of chemical substances during industrial sewage treatment. Chemosphere 159 (Supplement C), 619-627.

Suarez, S., Lema, J. M., Omil, F. 2010. Removal of Pharmaceutical and Personal Care Products (PPCPs) under nitrifying and denitrifying conditions. Water research 44 (10), 3214-3224.

Sun, Q., Chou, P., Peng, P., Yu, C. P. 2012. Transformation of Bisphenol A and Alkylphenols by Ammonia-Oxidizing Bacterial through Nitratation. Environmental Science and Technology $46,4442-4448$.

Tatarazako, N., Ishibashi, H., Teshima K, Kishi, K., and Arizono, K. 2004. Effects of triclosan on various organisms. Environmental Sciences 11 (2), 133-40. 
Ternes, T. A. 1998. Occurrence of drugs in German sewage treatment plants and rivers. Water Research 32 (11), 3245-3260.

Ternes, T. A., Herrmann, N., Bonerz, M., Knacker, T., Siegrist, H., Joss, A. 2004. A rapid method to measure the solid-water distribution coefficient $\left(\mathrm{K}_{\mathrm{d}}\right)$ for pharmaceuticals and musk fragrances in sewage sludge. Water Research 38 (19), 4075-4084.

U.S.EPA 2001. User's Guide for Water9 Software. Office of Air Quality Planning and Standards, U. S. Environmental Protection Agency, Research Triangle Park, NC.

Urase, T. and Kikuta, T. 2005. Separate estimation of adsorption and degradation of pharmaceutical substances and estrogens in the activated sludge process. Water Research 39 (7), 1289-1300.

Vanderford, B. J., Snyder, S. A. 2006. Analysis of pharmaceuticals in water by isotope dilution liquid chromatography/tandem mass spectrometry. Environmental Science and Technology 40 (23), 7312-20.

Vuono, D.C., Benecke, J., Henkel, J., Navidi, W.C., Cath, T.Y., Munakata-Marr, J., Spear, J.R., Drewes, J.E., 2015. Disturbance and temporal partitioning of the activated sludge metacommunity. The ISME Journal 9, 425-435. 
Wick, A., Fink, G., Joss, A., Siegrist, H., Ternes, T. A. 2009. Fate of beta blockers and psychoactive drugs in conventional wastewater treatment. Water research 43 (4), 1060-1074.

Xue, W., Wu, C., Xiao, K., Huang, X., Zhou, H., Tsuno, H., Tanaka, H. 2010. Elimination and fate of selected micro-organic pollutants in a full-scale anaerobic/anoxic/aerobic process combined with membrane bioreactor for municipal wastewater reclamation. Water research 44 (20), 5999-6010

Yan, Q., Gao, X., Chen, Y., Peng, X., Zhang, Y., Gan, X., Zi, C., Guo, J. 2014. Occurrence, fate and ecotoxicological assessment of pharmaceutically active compounds in wastewater and sludge from wastewater treatment plants in Chongqing, the Three Gorges Reservoir Area. Science of the Total Environment 470-471 (Supplement C), 618-630. 


\section{Supplementary Material}

\section{Biotransformation and Sorption of Trace Organic Compounds in Biological Nutrient Removal Treatment Systems}

Narasimman Lakshminarasimman ${ }^{\mathrm{a}}$, Oscar Quiñones ${ }^{\mathrm{b}}$, Brett J. Vanderford ${ }^{\mathrm{b}}$, Pablo MorenoCampo $^{c}$, Eric V. Dickenson ${ }^{b}$, Drew C. McAvoy ${ }^{a^{*}}$

a. Department of Chemical and Environmental Engineering, University of Cincinnati, Cincinnati, OH 45221, USA

b. Water Quality Research and Development Division, Southern Nevada Water Authority, Henderson, NV 89015, USA

c. Cranfield Water Science Institute, Cranfield University, Cranfield, Beds, MK43 0AL,UK

*Corresponding author:

Drew C. McAvoy

Department of Chemical and Environmental Engineering,

University of Cincinnati, Cincinnati, OH 45221, USA

E-mail: mcavoydm@ucmail.uc.edu 


\section{Structure and Properties of Selected TOrCs}

Table S-1. Structure and physico-chemical properties of selected TOrCs (http://toxnet.nlm.nih.gov).

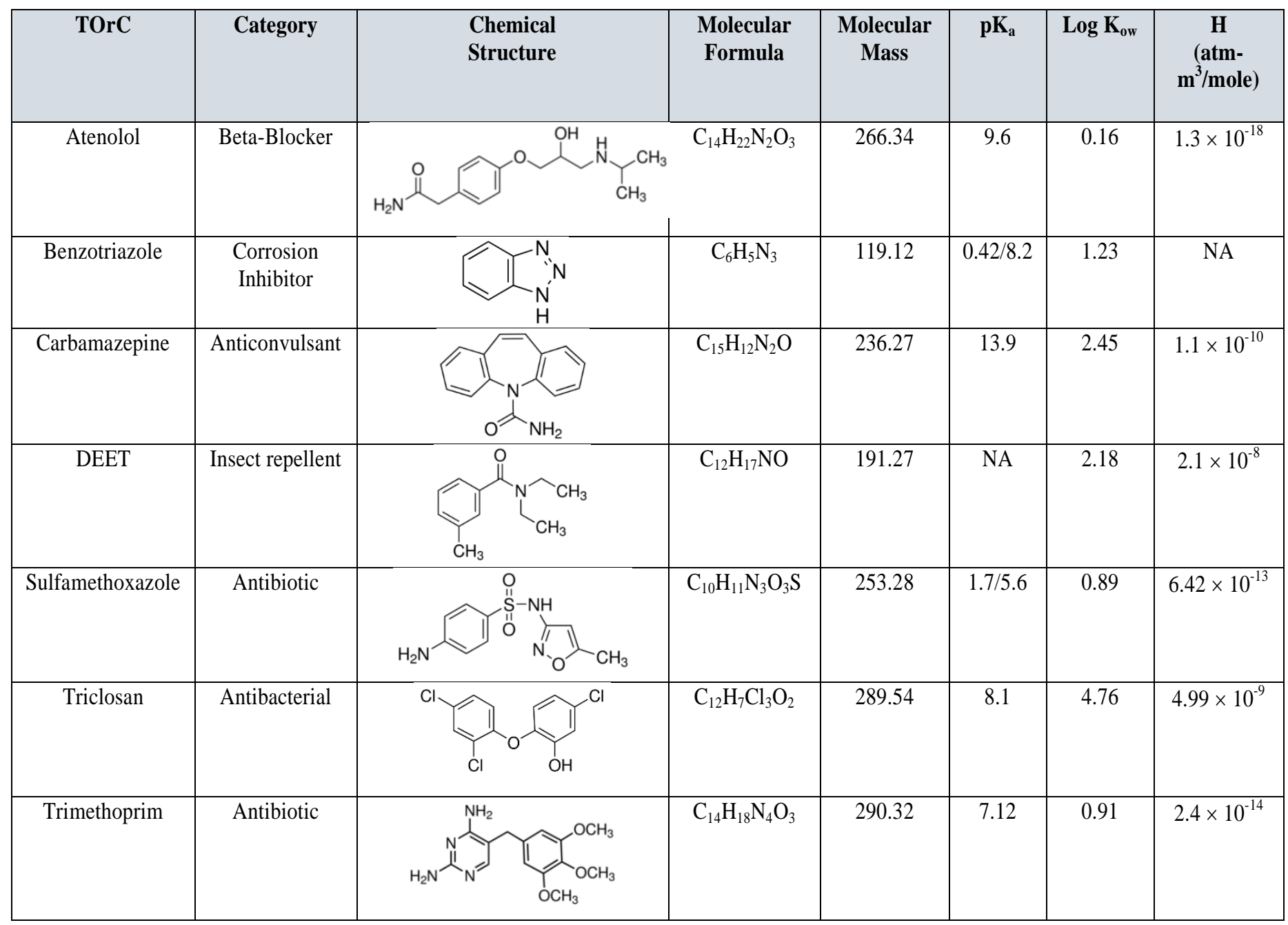


Table S-2. Source of Internal Standard and position of the deuterated label.

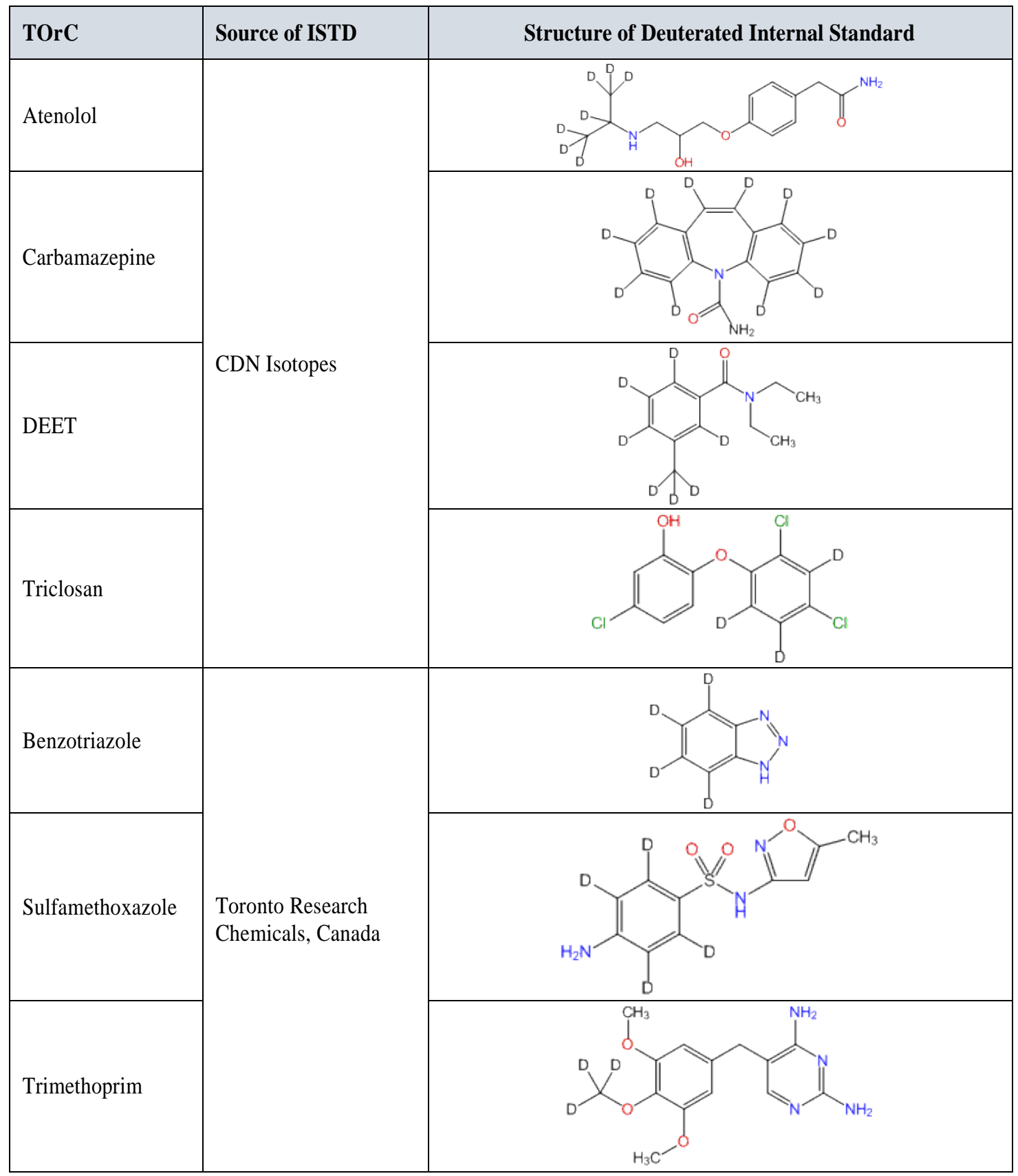




\section{WWTP Operational Data}

Table S-3. Treatment plant operating conditions during the sampling days for NV WWTP.

\begin{tabular}{|c|c|c|c|c|c|c|c|c|c|}
\hline \multirow[t]{2}{*}{ Date } & \multicolumn{9}{|c|}{ Effluent Water Quality } \\
\hline & $\begin{array}{l}\text { Flow } \\
\text { (MGD) }\end{array}$ & pH & $\begin{array}{c}\text { Temperature } \\
\left({ }^{\circ} \mathrm{C}\right)\end{array}$ & $\begin{array}{c}\text { Ortho-P } \\
\text { (mg-P/L) }\end{array}$ & $\begin{array}{c}\text { Total P } \\
(\mathrm{mg}-\mathrm{P} / \mathrm{L})\end{array}$ & $\begin{array}{l}\mathrm{NO}_{3}+\mathrm{NO}_{2} \\
(\mathrm{mg}-\mathrm{N} / \mathrm{L})\end{array}$ & $\begin{array}{c}\mathrm{NH}_{3} \\
(\mathrm{mg}-\mathrm{N} / \mathrm{L})\end{array}$ & $\begin{array}{c}\text { TKN } \\
(\mathrm{mg}-\mathrm{N} / \mathrm{L})\end{array}$ & $\begin{array}{l}\mathrm{cBOD}_{5} \\
(\mathrm{mg} / \mathrm{L})\end{array}$ \\
\hline $22-$ Oct-15 & 39.4 & 6.85 & 26.8 & 0.02 & 0.06 & N/A & $<0.10$ & N/A & $<2$ \\
\hline $10 / 20 / 2015^{*}$ & & & & & & 12.5 & & 1.2 & \\
\hline 19-Nov-15 & 39 & 6.78 & 23.3 & 0.04 & 0.08 & N/A & 0.27 & N/A & 2 \\
\hline $11 / 17 / 2015^{*}$ & & & & & & 17.2 & & $<1.0$ & \\
\hline 11-Jan-16 & 46.6 & 6.70 & 20.5 & 0.07 & 0.13 & N/A & 0.82 & N/A & 2 \\
\hline $1 / 12 / 2016^{*}$ & & & & & & 17.4 & & 2.2 & \\
\hline 5-May-16 & 40.9 & 6.77 & 25.9 & 0.16 & 0.21 & N/A & $<0.10$ & N/A & $<2$ \\
\hline $5 / 3 / 2016^{*}$ & & & & & & 15.6 & & 1.1 & \\
\hline $17-$ Oct-16 & 36.7 & 6.86 & 26.1 & 0.27 & 0.32 & N/A & $<0.10$ & N/A & $<2$ \\
\hline 10/18/2016* & & & & & & 15.2 & & $<1.0$ & \\
\hline
\end{tabular}

$* \mathrm{NO}_{3}+\mathrm{NO}_{2}$ and TKN were not analyzed on sampling day, results are for the Tuesday of same week as sampled

Table S-4. Treatment plant operating conditions during the sampling days for OH WWTP.

\begin{tabular}{|c|c|c|c|c|c|c|c|}
\hline \multirow{2}{*}{ Date } & \multicolumn{6}{|l}{ Effluent Water Quality } \\
\cline { 2 - 8 } & $\begin{array}{c}\text { Flow } \\
(\mathbf{M G D})\end{array}$ & $\mathbf{p H}$ & $\begin{array}{c}\text { Temperature } \\
\left({ }^{\mathbf{0}} \mathbf{C}\right)\end{array}$ & $\begin{array}{c}\text { Turbidity } \\
(\mathbf{N T U})\end{array}$ & $\begin{array}{c}\text { Total P } \\
(\mathbf{m g}-\mathbf{P} / \mathbf{L})\end{array}$ & $\begin{array}{c}\mathbf{c B O D} \\
(\mathbf{m g} / \mathbf{L})\end{array}$ & $\begin{array}{c}\mathbf{N H}_{\mathbf{3}} \\
(\mathbf{m g}-\mathbf{N} / \mathbf{L})\end{array}$ \\
\hline 15-June-15 & 5.21 & 7.4 & 22 & 2.3 & 0.11 & 3 & 0.05 \\
\hline 19-July-15 & 11.23 & 7.7 & 22 & 2.2 & NA & NA & NA \\
\hline 19-Sep-15 & 4.36 & 7.9 & 22 & 1.2 & NA & NA & NA \\
\hline
\end{tabular}

NA - Not Analyzed 


\section{LC MS/MS Analysis Instrumental Parameters}

Table S-5. MRM transitions and MS operating parameters used for the analysis of TOrCs in positive mode (ESI+) and negative mode (ESI-) for biotransformation experiment.

\begin{tabular}{|c|c|c|c|c|c|c|c|}
\hline Target Analyte & $\begin{array}{c}\text { Q1 } \\
\text { Mass }\end{array}$ & $\begin{array}{c}\text { Q3 } \\
\text { Mass }\end{array}$ & $\begin{array}{l}\text { Retention } \\
\text { Time (min) }\end{array}$ & $\begin{array}{l}\text { DP } \\
(V)\end{array}$ & $\begin{array}{l}\text { EP } \\
(V)\end{array}$ & $\begin{array}{l}\text { CE } \\
\text { (V) }\end{array}$ & $\begin{array}{r}\text { CXP } \\
(\mathrm{V})\end{array}$ \\
\hline Sulfamethoxazole & 254 & 156 & 3.7 & 66 & 10 & 23 & 10 \\
\hline $\begin{array}{c}\text { Sulfamethoxazole } \\
\text { confirmation }\end{array}$ & 254 & 92 & 3.7 & 66 & 10 & 41 & 6 \\
\hline Sulfamethoxazole- $\mathrm{d}_{4}$ & 258 & 160 & 3.7 & 56 & 10 & 25 & 12 \\
\hline DEET & 192 & 119 & 7.9 & 76 & 10 & 25 & 10 \\
\hline DEET confirmation & 192 & 91 & 7.9 & 76 & 10 & 41 & 6 \\
\hline DEET- $\mathrm{d}_{7}$ & 199 & 126 & 7.9 & 76 & 10 & 25 & 10 \\
\hline Benzotriazole & 120 & 92 & 4.6 & 45 & 12 & 29 & 10 \\
\hline Benzotriazole confirmation & 120 & 65 & 4.6 & 45 & 12 & 33 & 12 \\
\hline Benzotriazole- $\mathrm{d}_{4}$ & 124 & 69 & 4.6 & 45 & 12 & 33 & 14 \\
\hline Atenolol & 267 & 145 & 3.3 & 65 & 10 & 35 & 10 \\
\hline Atenolol confirmation & 267 & 116 & 3.3 & 65 & 10 & 28 & 10 \\
\hline Atenolol-d $\mathrm{d}_{7}$ & 274 & 145 & 3.3 & 61 & 10 & 37 & 10 \\
\hline Trimethoprim & 291 & 261 & 5.0 & 81 & 10 & 35 & 8 \\
\hline Trimethoprim confirmation & 291 & 123 & 5.0 & 81 & 10 & 32 & 12 \\
\hline Trimethoprim- $\mathrm{d}_{9}$ & 300 & 234 & 5.0 & 71 & 10 & 35 & 16 \\
\hline Carbamazepine & 237 & 165 & 7.7 & 90 & 10 & 57 & 10 \\
\hline $\begin{array}{l}\text { Carbamazepine } \\
\text { confirmation }\end{array}$ & 237 & 194 & 7.7 & 90 & 10 & 27 & 10 \\
\hline Carbamazepine- $d_{10}$ & 247 & 204 & 7.7 & 61 & 10 & 31 & 20 \\
\hline Triclosan & 287 & 35 & 5.2 & -45 & -10 & -30 & -4 \\
\hline Triclosan confirmation & 289 & 37 & 5.2 & -45 & -10 & -30 & -4 \\
\hline Triclosan- $\mathrm{d}_{3}$ & 294 & 37 & 5.2 & -45 & -10 & -30 & -4 \\
\hline
\end{tabular}


Table S-6. MRM transitions and MS operating parameters used for the analysis of TOrCs in positive mode (ESI+) and negative mode (ESI-) for the sorption experiment.

\begin{tabular}{|c|c|c|c|c|c|c|}
\hline Compound & $\begin{array}{l}\text { Fragmentor } \\
\text { Voltage (V) }\end{array}$ & $\begin{array}{c}\text { MRM } \\
\text { Transitions } \\
(\mathbf{m} / \mathbf{z})\end{array}$ & $\begin{array}{l}\text { Collision } \\
\text { Energy }\end{array}$ & $\begin{array}{l}\text { Dwell } \\
\text { Time } \\
\text { (msec) }\end{array}$ & Group & $\begin{array}{c}\text { Retention } \\
\text { Time } \\
\text { (min) }\end{array}$ \\
\hline Benzotriazole & 200 & $120=>65$ & 29 & 100 & ESI+ & 3.0 \\
\hline Benzotriazole- $\mathrm{d}_{4}$ & 200 & $124=>65$ & 33 & 100 & ESI+ & 3.0 \\
\hline Sulfamethoxazole & 110 & $254=>156$ & 15 & 100 & ESI+ & 4.2 \\
\hline Sulfamethoxazole- $\mathrm{d}_{4}$ & 110 & $258=>160$ & 25 & 100 & ESI+ & 4.2 \\
\hline Carbamazepine & 110 & $237 \Rightarrow 194$ & 15 & 100 & ESI+ & 5.3 \\
\hline Carbamazepine- $\mathrm{d}_{10}$ & 110 & $247 \Rightarrow 204$ & 15 & 100 & ESI+ & 5.3 \\
\hline DEET & 110 & $192=>119$ & 15 & 100 & ESI+ & 5.9 \\
\hline DEET-d ${ }_{7}$ & 110 & $199 \Rightarrow 126$ & 15 & 100 & ESI+ & 5.9 \\
\hline Triclosan & 75 & $287=>35$ & 5 & 100 & ESI- & 7.2 \\
\hline Triclosan- $\mathrm{d}_{4}$ & 75 & $294=>37$ & 5 & 100 & ESI- & 7.2 \\
\hline
\end{tabular}




\section{Analysis of Conventional Parameters}

Analytical methods for the conventional parameters are provided in Table S-7. Results of subsamples from the field-sample carboys prior to dosing are provided in Table S-8. These samples were taken approximately 90 min prior to dosing the TOrCs.

Table S-7. Analytical Methods for Conventional Parameters.

\begin{tabular}{|l|l|}
\hline \multicolumn{1}{|c|}{ Parameter } & \multicolumn{1}{c|}{ Analysis Method } \\
\hline $\mathrm{pH}$ & Standard Method 4500-H B \\
\hline $\mathrm{TSS} / \mathrm{VSS}$ & Standard Methods 2540 D \\
\hline $\mathrm{NO}_{2} / \mathrm{NO}_{3} / \mathrm{PO}_{4}$ & $\begin{array}{l}\text { Standard Method 4110B Ion } \\
\text { Chromatography }\end{array}$ \\
\hline $\mathrm{NH}_{3}$ & Standard Method 4500-NH $3 \mathrm{D}$ \\
\hline $\mathrm{TKN}$ & $\begin{array}{l}\text { Method 8075 Total Kjeldahl, Hach } \\
\text { Company }\end{array}$ \\
\hline COD & Method 8000 COD, Hach Company \\
\hline DOC & Standard Method 5310 B \\
\hline DO & Standard Method 4500-O G \\
\hline
\end{tabular}

Table S-8. Conventional parameter results for activated sludge collected from two BNR treatment plants $(\mathrm{OH}$ and NV). Results in Mean \pm SD $(n=3)$.

\begin{tabular}{|c|c|c|c|c|c|c|}
\hline \multirow[b]{2}{*}{$\begin{array}{l}\text { Conventional } \\
\text { Parameter } \\
(\mathrm{mg} / \mathrm{L})\end{array}$} & \multicolumn{3}{|c|}{$\mathbf{O H}$} & \multicolumn{3}{|c|}{ NV } \\
\hline & $\begin{array}{c}\text { Anaerobic } \\
\text { (July 19, } \\
\text { 2015) } \\
\end{array}$ & $\begin{array}{c}\text { Anoxic } \\
\text { (September } \\
\text { 18, 2015) } \\
\end{array}$ & $\begin{array}{c}\text { Aerobic } \\
\text { (June 15, } \\
\text { 2015) } \\
\end{array}$ & $\begin{array}{c}\begin{array}{c}\text { Anaerobic } \\
\text { (January } \\
11,2016)\end{array} \\
\end{array}$ & $\begin{array}{c}\text { Anoxic } \\
\text { (Novembe } \\
\text { r 19, 2015) } \\
\end{array}$ & $\begin{array}{l}\text { Aerobic } \\
\text { (October } \\
\text { 22, 2015) }\end{array}$ \\
\hline $\mathrm{pH}$ & 7.3 & 7.8 & 7.2 & 7.0 & 6.7 & 6.8 \\
\hline TSS & $1713 \pm 90$ & $3387 \pm 116$ & $3497 \pm 67$ & $1720 \pm 87$ & $3860 \pm 296$ & $2550 \pm 71$ \\
\hline VSS & $1427 \pm 101$ & $2453 \pm 190$ & $2613 \pm 51$ & $1328 \pm 50$ & $2713 \pm 205$ & $1910 \pm 212$ \\
\hline Total COD & $1897 \pm 40$ & $4070 \pm 211$ & $4837 \pm 209$ & $1867 \pm 91$ & $3317 \pm 413$ & $3783 \pm 321$ \\
\hline sCOD & $20 \pm 5$ & $22 \pm 3.47$ & $12.7 \pm 2.1$ & $60 \pm 6$ & $33 \pm 1$ & $31.3 \pm 3.2$ \\
\hline pCOD & 1876 & 4048 & $4824 \pm 210$ & 1807 & 3284 & 3752 \\
\hline DOC & $7.4 \pm 0$ & $10.7 \pm 0$ & $6.2 \pm 0.1$ & NA & $9.2 \pm 0.1$ & $8.5 \pm 0.1$ \\
\hline $\mathrm{sNH}_{3}-\mathrm{N}$ & $4.6 \pm 1$ & $3.6 \pm 0.2$ & $0.22 \pm 0$ & $24.7 \pm 0.7$ & $4.2 \pm 0.3$ & $0.9 \pm 0$ \\
\hline $\mathrm{sNO}_{2}-\mathrm{N}$ & $<0.1$ & $<0.1$ & $<0.1$ & $<0.1$ & $<0.1$ & $<0.1$ \\
\hline $\mathrm{sNO}_{3}-\mathrm{N}$ & $<0.1$ & $0.61 \pm 0$ & $0.11 \pm 0$ & $<0.1$ & $2.4 \pm 0$ & $4.36 \pm 0$ \\
\hline $\mathrm{sPO}_{4}-\mathrm{P}$ & $3.5 \pm 0.2$ & $2.4 \pm 0.2$ & $<0.1$ & $1.6 \pm 0.2$ & $1.4 \pm 0$ & $0.9 \pm 0.2$ \\
\hline
\end{tabular}

NA - Not Analyzed 
The conventional parameters results from the six biotransformation experiments are provided in Figures S-1 to S-3. A general observation for the conventional parameters in the biotic and abiotic reactors was that they behaved similarly over the time course of the studies.

$\underline{p H}$ : Initial $\mathrm{pH}$ of the original activated sludge from $\mathrm{OH}$ was higher than $\mathrm{NV}$ for all three redox conditions (Table S-8). For the $\mathrm{OH}$ experiments, the buffer addition held the $\mathrm{pH}$ close to 8.0 in the two biotic reactors under all three redox conditions and between $7.1-7.5$ in the abiotic controls for all three redox conditions (Figures S-1 to S-3). Results were similar for the NV activated sludge experiments, except the $\mathrm{pH}$ in the anoxic biotic reactors decreased from 8 to 6.9 over the $72 \mathrm{~h}$ study period (Figure S-3 b, d). The abiotic controls in all of the NV activated sludge experiments decreased due to the presence of the biocide (aerobic: $7.4-6.9$; anaerobic: $7.6-6.9$; anoxic: $7.3-6.7$ ). This decrease in $\mathrm{pH}$ was due to the removal of alkalinity from solution via precipitation reactions with the biocide (as seen visually).

Dissolved Oxygen: A DO > $4 \mathrm{mg} / \mathrm{L}$ was maintained in the aerobic experiment reactors and a DO $<0.1 \mathrm{mg} / \mathrm{L}$ was maintained in the anoxic and anaerobic experiments reactors.

Total/Volatile Suspended Solids: Total and volatile suspended solids (TSS/VSS) were similar in the initial activated sludge from both treatment plants with the exception of VSS in the NV aerobic activated sludge $(1910 \pm 212 \mathrm{mg} / \mathrm{L})$, which was less than the VSS in the OH activated sludge $(2613 \pm 51 \mathrm{mg} / \mathrm{L})$. Generally, the TSS and VSS values decreased with time in all experiments indicating a decay of biomass. Also, the solids concentration values were higher in the abiotic control reactor when compared to the biotic reactors, which may be due to the formation of precipitates by the biocide (as seen visually). In the anaerobic experiment using $\mathrm{OH}$ activated sludge, the mixer in one of the biotic reactors failed on day 1 and it was not fixed until day 3. So the day 1 solids sample was not representative. Since the reactor remained anaerobic during this time period, the lack of mixing was not expected to affect degradation of the target TOrCs. Thus, a day 5 sample was collected from biotic reactor B for conventional parameters and TOrC analyses.

Chemical Oxygen Demand: An increase in total and soluble COD concentrations was observed for the time zero samples. This increase in COD was due, in part, to the addition of methanol in the TOrC spiking solution (30 mg of COD/L), but the methanol does not explain the entire increase in total COD, which may be due to hydrolysis of the solids during the $90 \mathrm{~min}$ equilibration period prior to the methanol addition. In general, the pCOD decreased over time which corresponded with a decrease in VSS over time. This decrease in pCOD and VSS suggests that bacterial cell lysis may be occurring during the experiments. The SCOD decreased in both the aerobic experiments (Figure S-1) indicating substrate utilization by heterotrophic microorganisms. The sCOD increased in the anaerobic experiments (Figure S-2) was possibly due to fermentation. In the anoxic experiment SCOD deceased overtime for NV activated sludge (Figures S-3 b, d), whereas in the $\mathrm{OH}$ anoxic experiment it either increased (Figure S-3a) or remained the same (Figure $\mathrm{S}-3 \mathrm{c}$ ). 
Dissolved Organic Carbon: Similar to sCOD, DOC in the reactors increased from the original aerobic activated sludge to the time zero sampling and was due, in part, to the methanol addition from the TOrC spiking solution ( $7.5 \mathrm{mg}-\mathrm{C} / \mathrm{L})$. However, this amount of DOC from methanol does not explain the observed increase of $15-20 \mathrm{mg}-\mathrm{C} / \mathrm{L}$ over the $90 \mathrm{~min}$ equilibration period. During the experiments, DOC decreased over time in the aerobic and anoxic biotic reactors due to carbon utilization and by the end of the experiments the DOC concentration had dropped to background levels (Figures S-1 and S-3). DOC in all of the abiotic controls increased over time, which was probably due to cell lysis by the biocide. Again, similar to sCOD, DOC increased in the biotic reactors of the $\mathrm{OH}$ anaerobic experiment (Figures S-2 a, c), which could be due to fermentation.

Nutrients ( $\mathrm{NH}_{3}-\mathrm{N}, \mathrm{NO}_{3}-\mathrm{N}, \mathrm{NO}_{2}-\mathrm{N}$ and $\left.\mathrm{PO}_{4}-\mathrm{P}\right)$ : Concentrations of soluble $\mathrm{NH}_{3}-\mathrm{N}(<0.1 \mathrm{mg} / \mathrm{L})$, $\mathrm{NO}_{2}-\mathrm{N}(<1.0 \mathrm{mg} / \mathrm{L}), \mathrm{NO}_{3}-\mathrm{N}(<1.0 \mathrm{mg} / \mathrm{L})$, and $\mathrm{PO}_{4}-\mathrm{P}(<1.0 \mathrm{mg} / \mathrm{L})$ in the original aerobic activated sludge from $\mathrm{OH}$ were quite low indicating that the BNR treatment process was operating properly for removing $\mathrm{N}$ and $\mathrm{P}$ from the wastewater. In the $\mathrm{OH}$ aerobic experiment, the phosphate spike $(10 \mathrm{mg} \mathrm{PO}-\mathrm{P} / \mathrm{L})$ was readily taken up during the 90 min equilibration period prior to time zero indicating the phosphate accumulating bacteria were active with phosphate values near the original activated sludge concentration of $1.5 \mathrm{mg} / \mathrm{L}$. Phosphorus uptake was also observed in the $\mathrm{NV}$ aerobic experiment. A significant increase in $\mathrm{NO}_{3}-\mathrm{N}$ and decrease in $\mathrm{NH}_{3}-\mathrm{N}$ was seen in both the aerobic experiments (Figures $\mathrm{S}-1 \mathrm{a}-\mathrm{d}$ ) indicating nitrification by nitrifying bacteria. Nitrate uptake during the anoxic experiments are shown in Figures S-3 a-d. The nitrate concentration in the reactors increased overtime due to the addition of $30 \mathrm{mg} \mathrm{NO}$ - $\mathrm{N} / \mathrm{L}$ every 12 hours to maintain anoxic conditions. Overall, the nutrient trends demonstrated not only that relevant redox conditions were maintained, but also relevant microbial population were active through the experiment. 

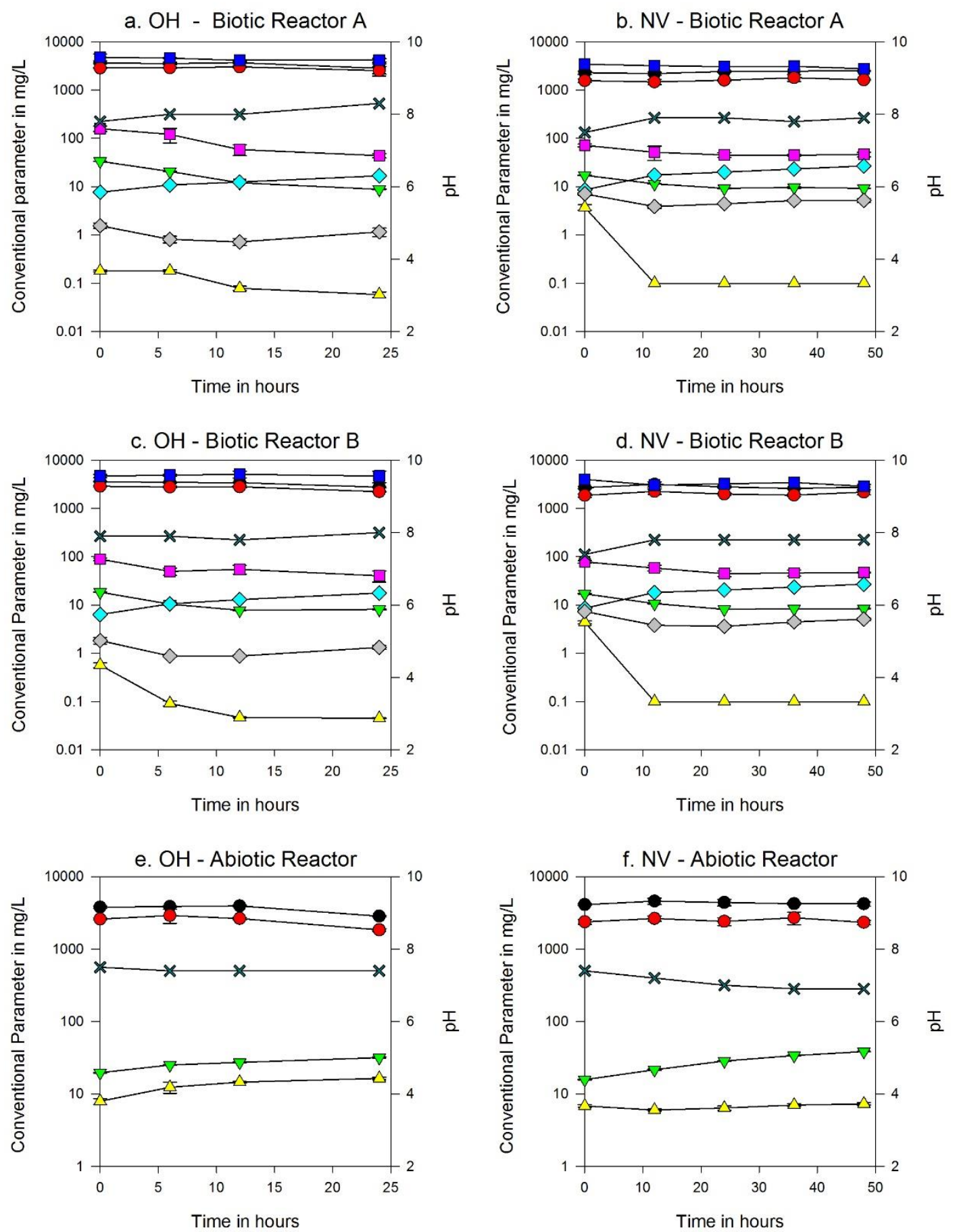

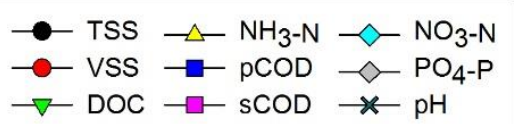

Figure S-1. Conventional parameter results in aerobic biotransformation experiments. 
a. $\mathrm{OH}$ - Biotic Reactor $\mathrm{A}$

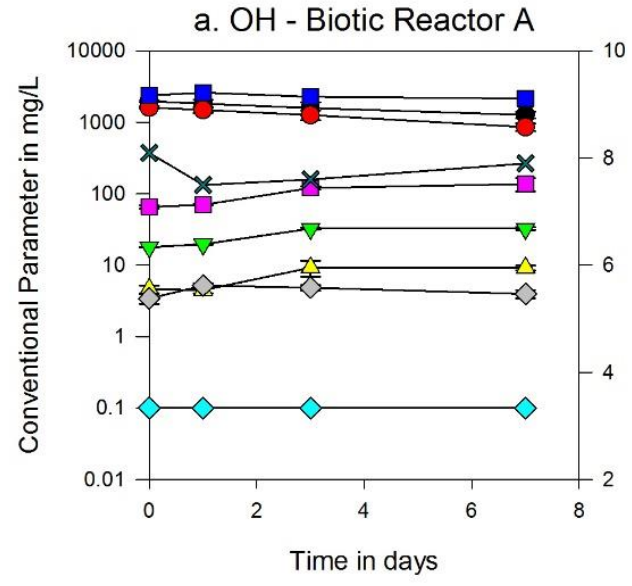

c. $\mathrm{OH}$ - Biotic Reactor $\mathrm{B}$

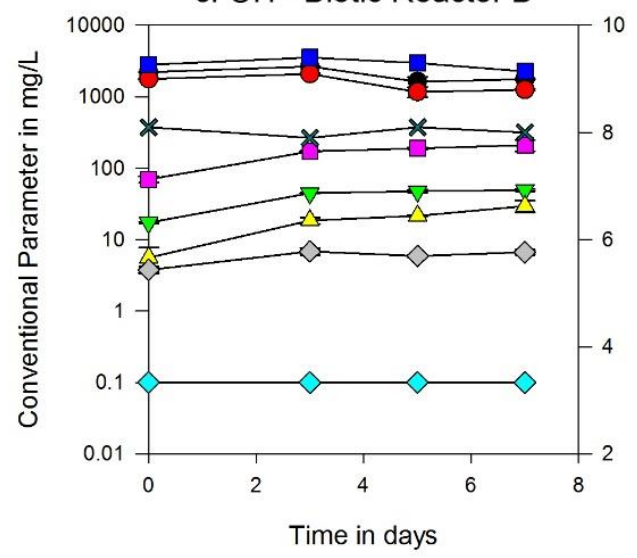

e. $\mathrm{OH}$ - Abiotic Reactor

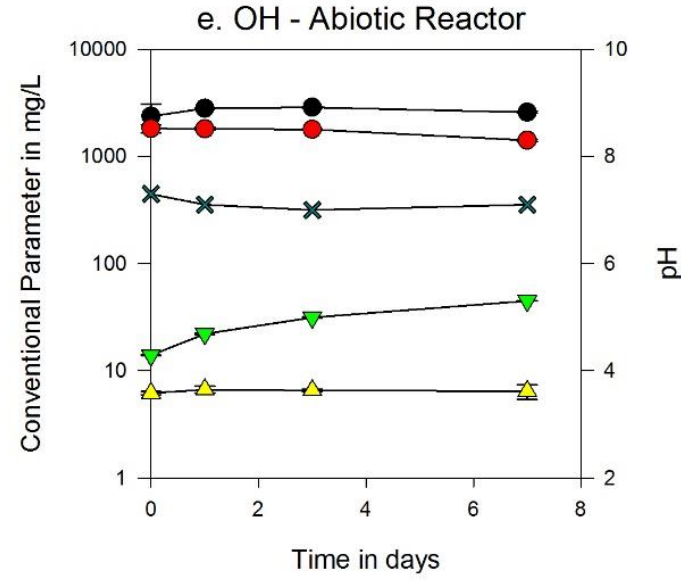

b. NV - Biotic Reactor A

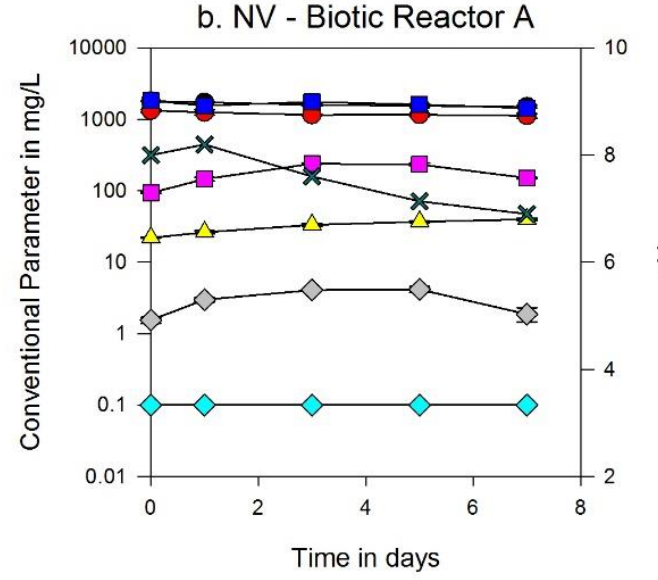

d. NV - Biotic Reactor B
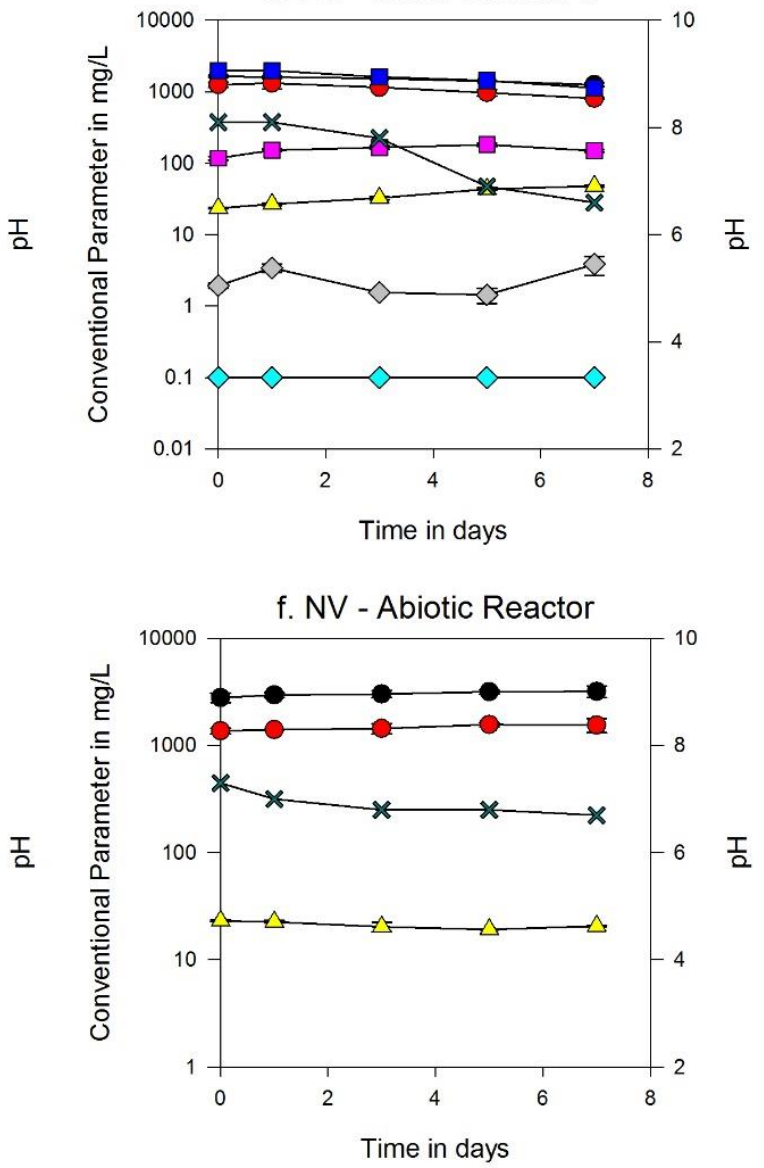

Figure S-2. Conventional parameter results in anaerobic biotransformation experiments. 
a. $\mathrm{OH}$ - Biotic Reactor $\mathrm{A}$

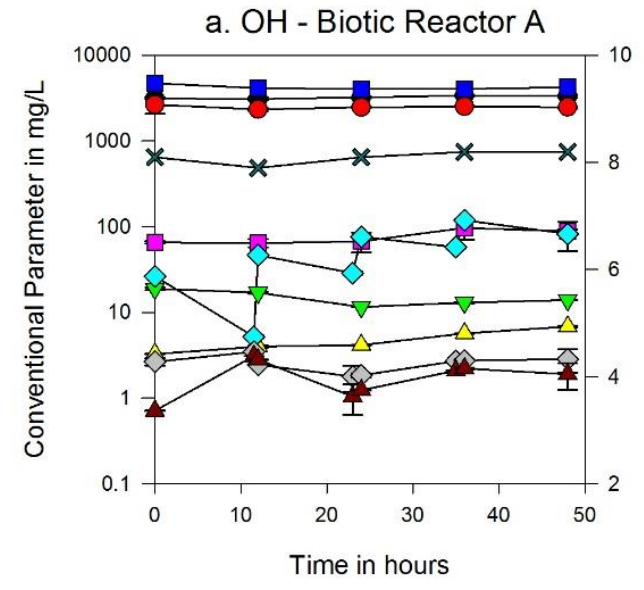

c. $\mathrm{OH}$ - Biotic Reactor B

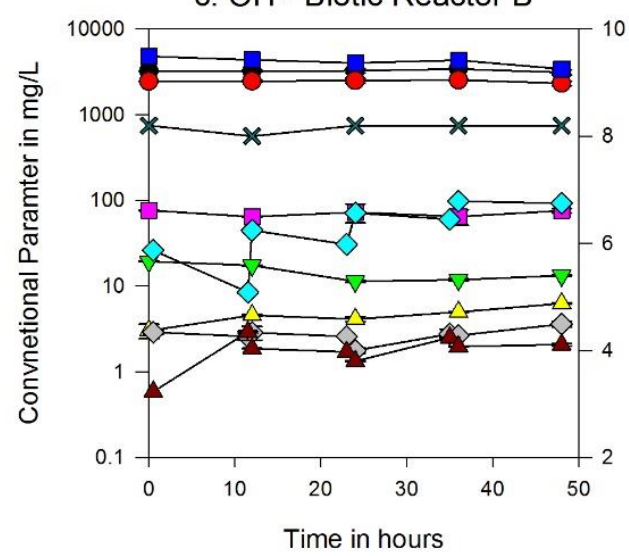

e. $\mathrm{OH}$ - Abiotic Reactor

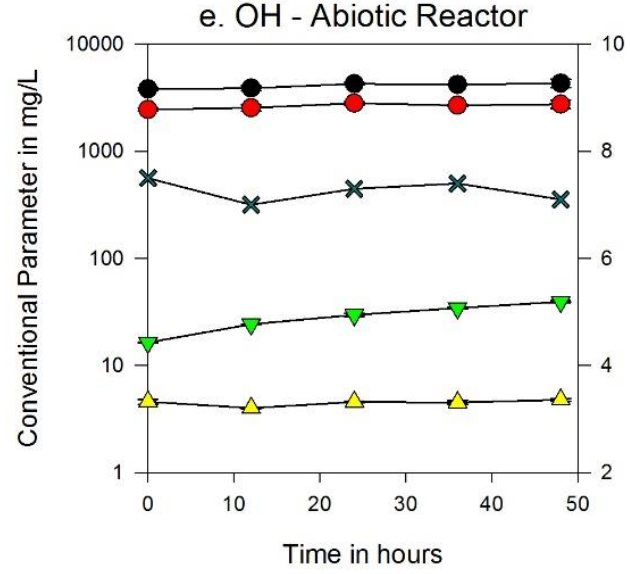

Time in hours
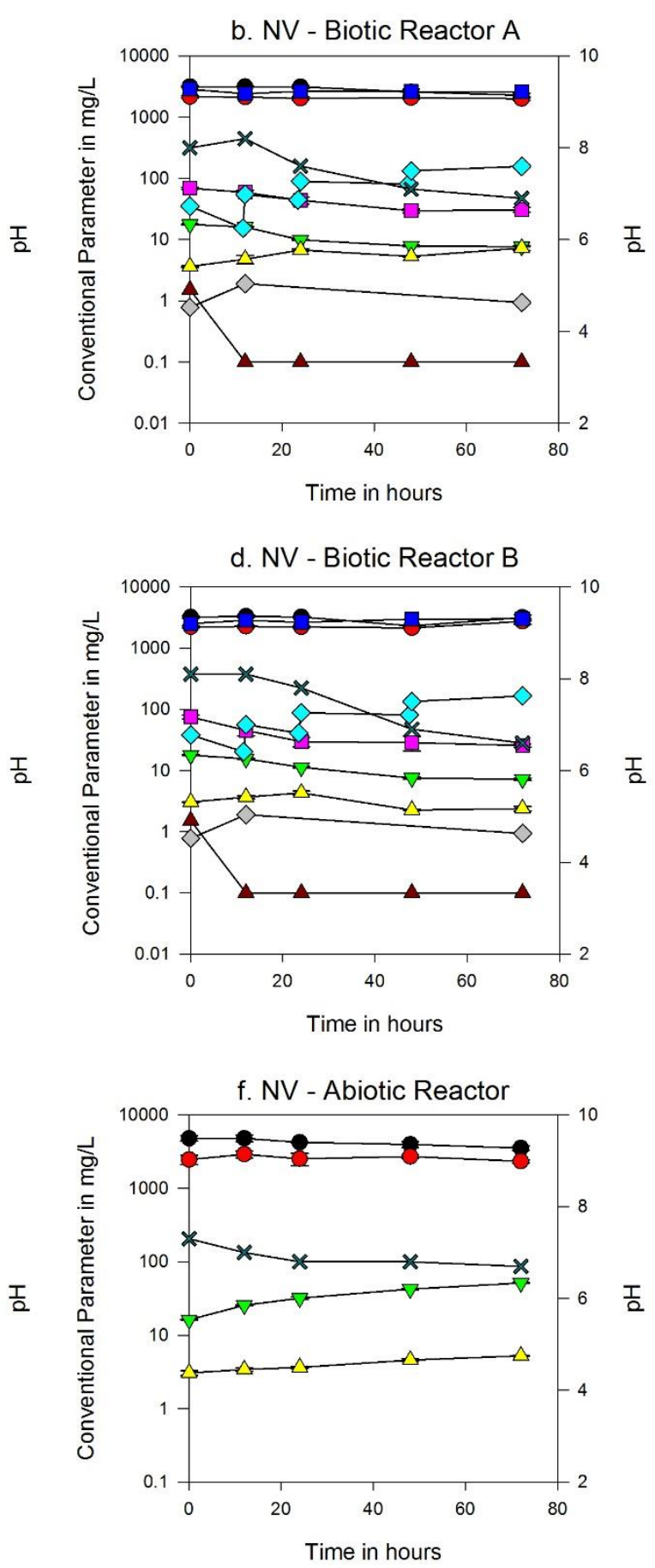

Figure S-3. Conventional parameter results in anoxic biotransformation experiments. 


\section{TOrCs Analysis}

a. Trimethoprim - $\mathrm{OH}$

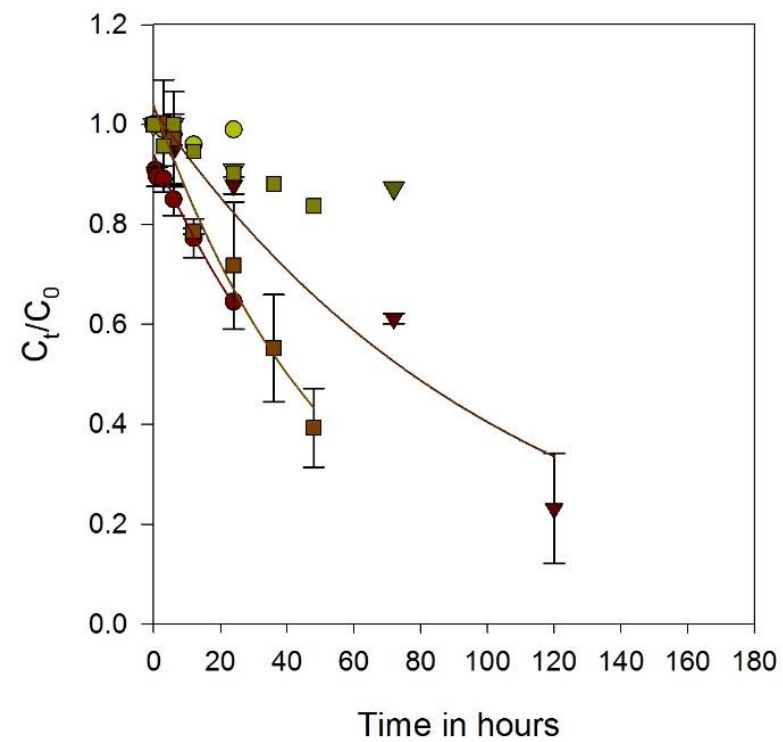

c. Atenolol - OH

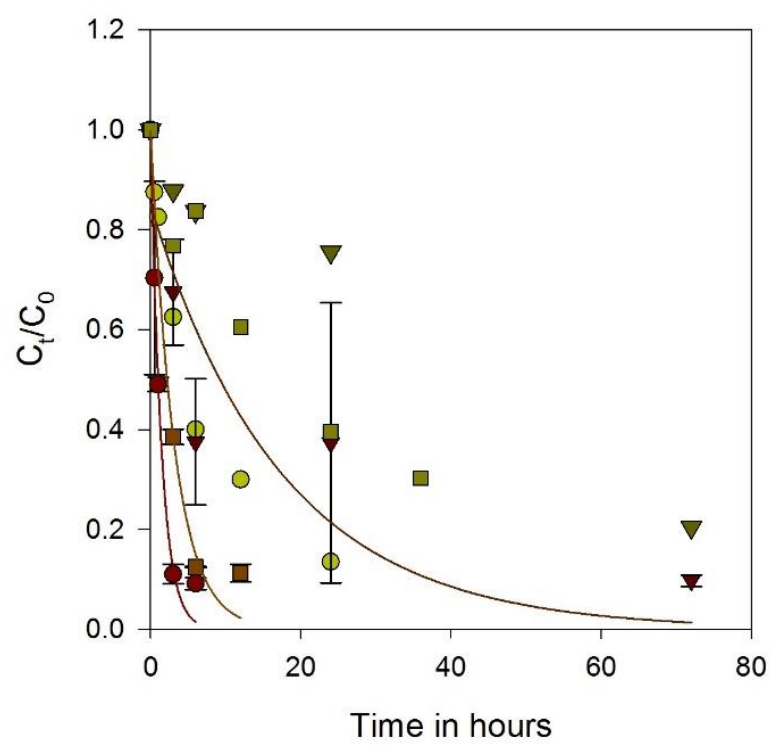

b. Trimethoprim - NV

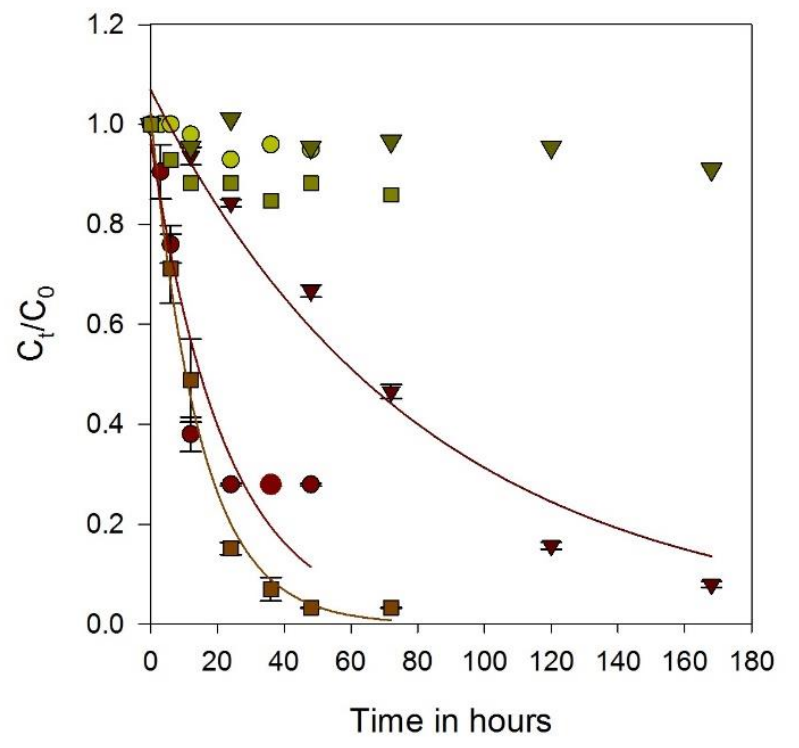

d. Atenolol - NV

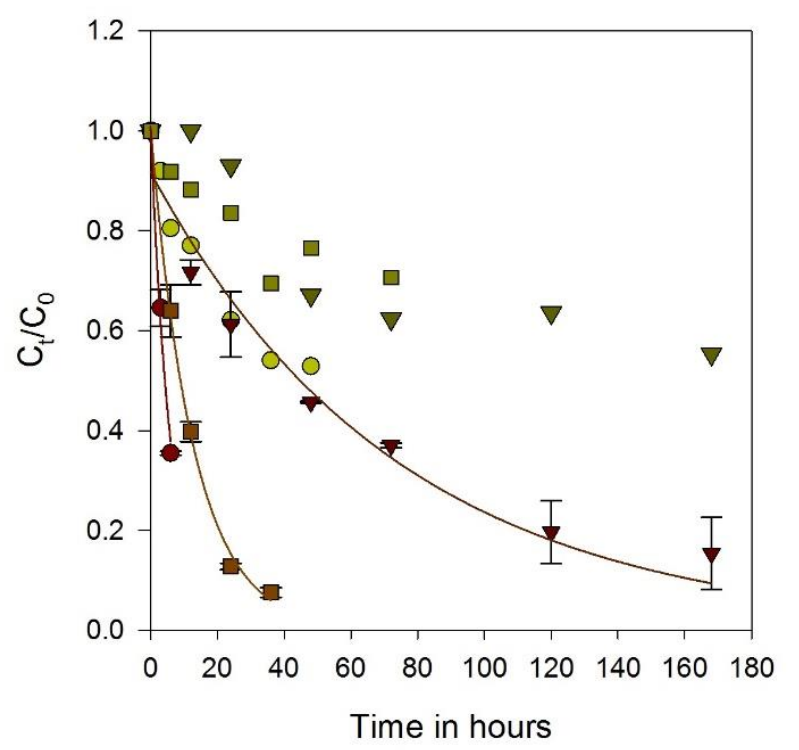

Figures S-4 (a,b,c,d). Biotransformation profiles for atenolol and trimethoprim in biotic and abiotic reactors containing activated sludge from aerobic, anaerobic and anoxic redox conditions in $\mathrm{OH}$ and NV BNR treatment plants. 
e. Carbamazepine - $\mathrm{OH}$

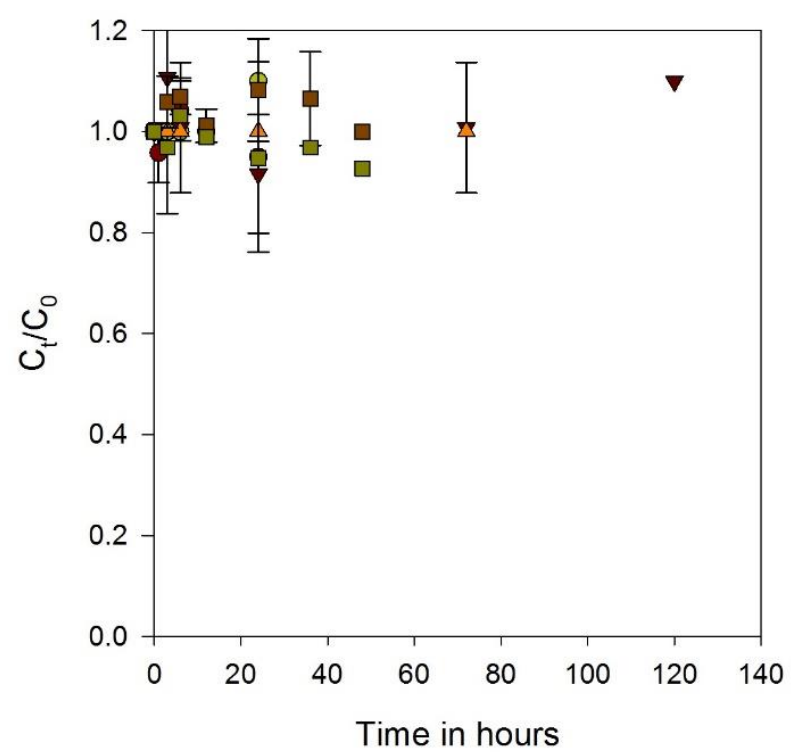

g. Sulfamethoxazole - $\mathrm{OH}$

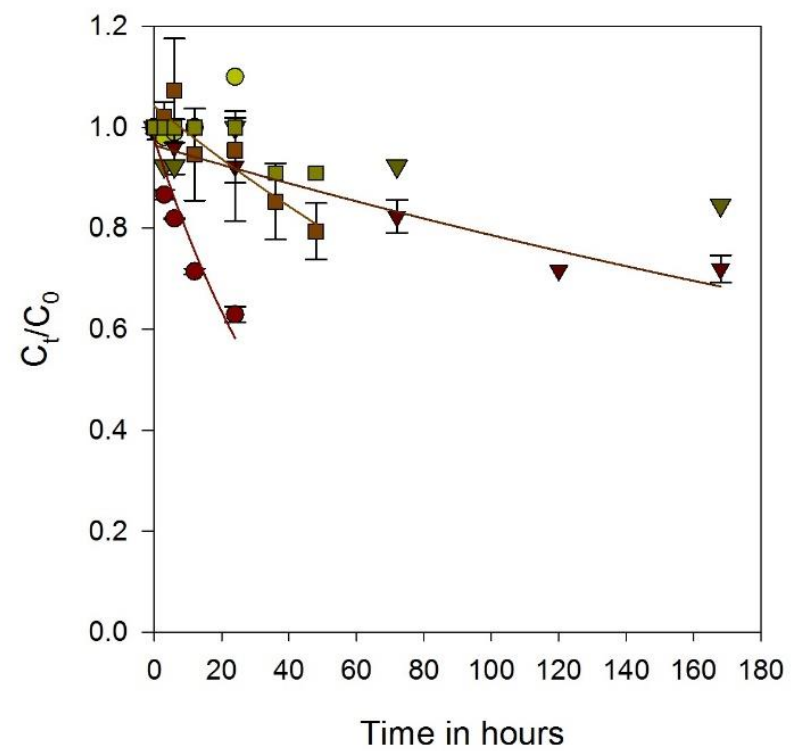

f. Carbamezepine - NV

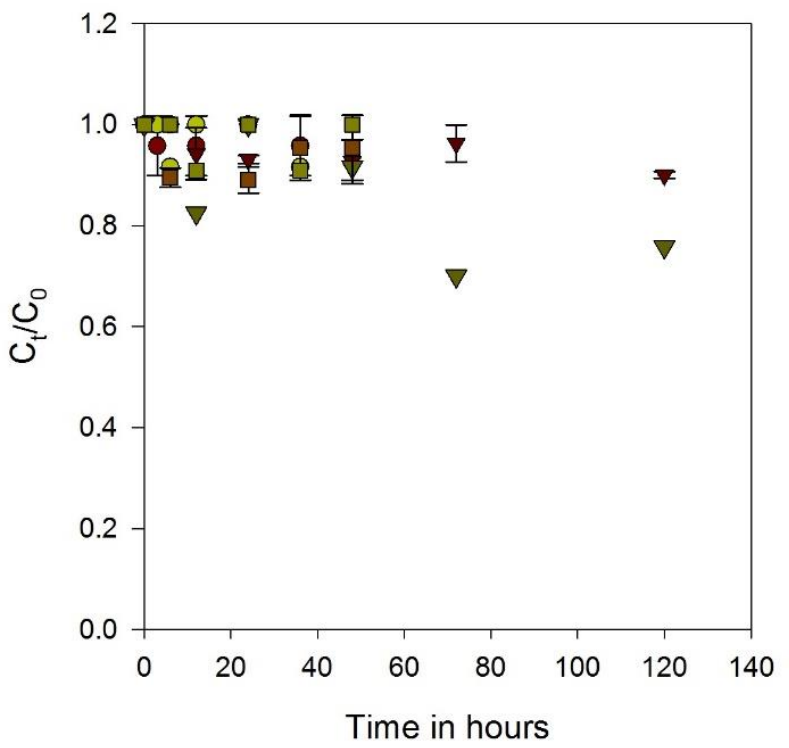

h. Sulfamethoxazole - NV

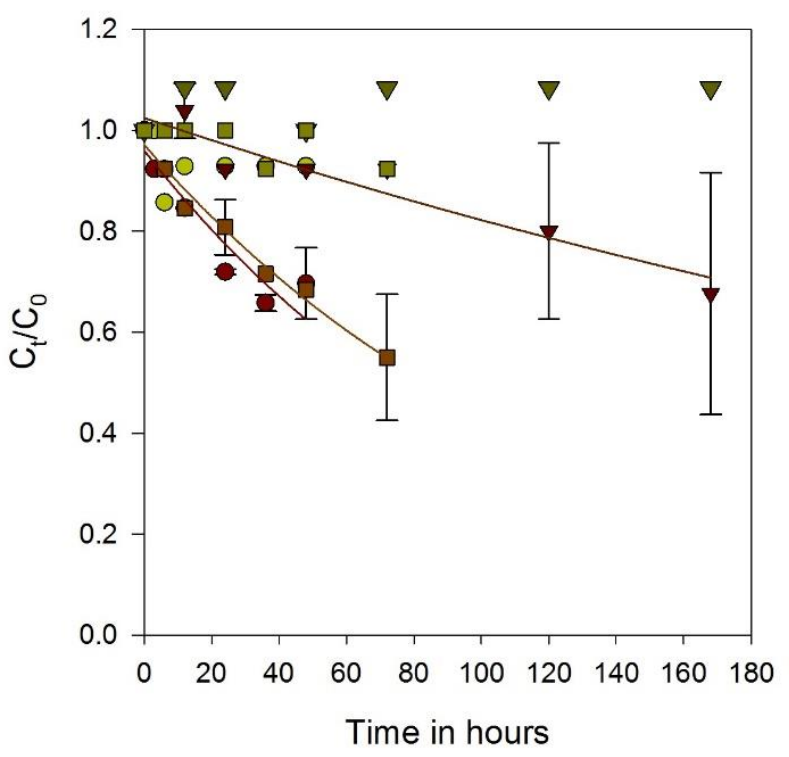

- Aerobic - Biotic

- Aerobic - Abiotic

$\nabla$ Anaerobic - Biotic $\square$ Anoxic - Biotic Anaerobic-Abiotic $\square$ Anoxic-Biotic

Figures S-4 (e,f,g,h). Biotransformation profiles for carbamazepine and sulfamethoxazole in biotic and abiotic reactors containing activated sludge from aerobic, anaerobic and anoxic redox conditions in OH and NV BNR treatment plants. 
i. DEET - $\mathrm{OH}$

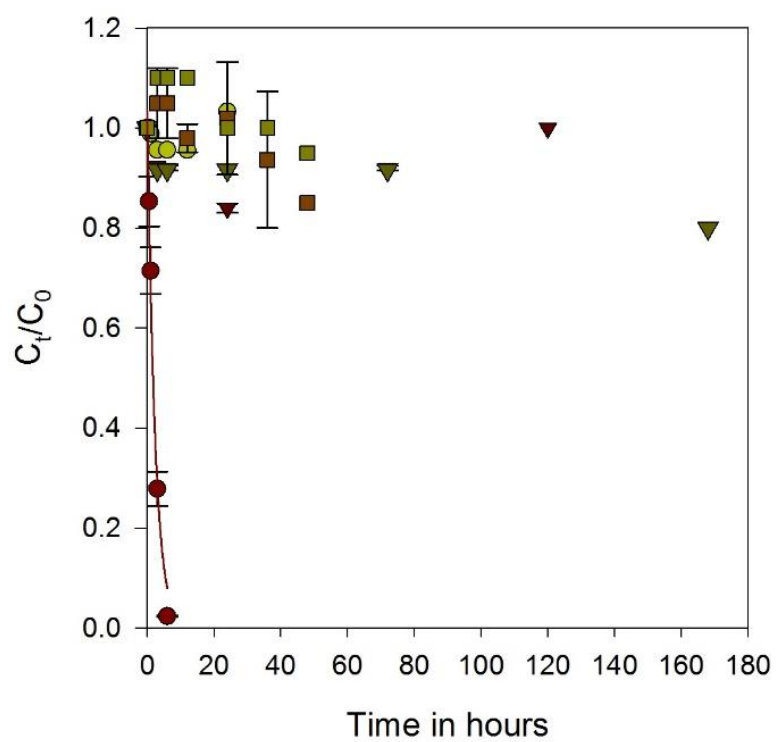

k. Benzotriazole - $\mathrm{OH}$

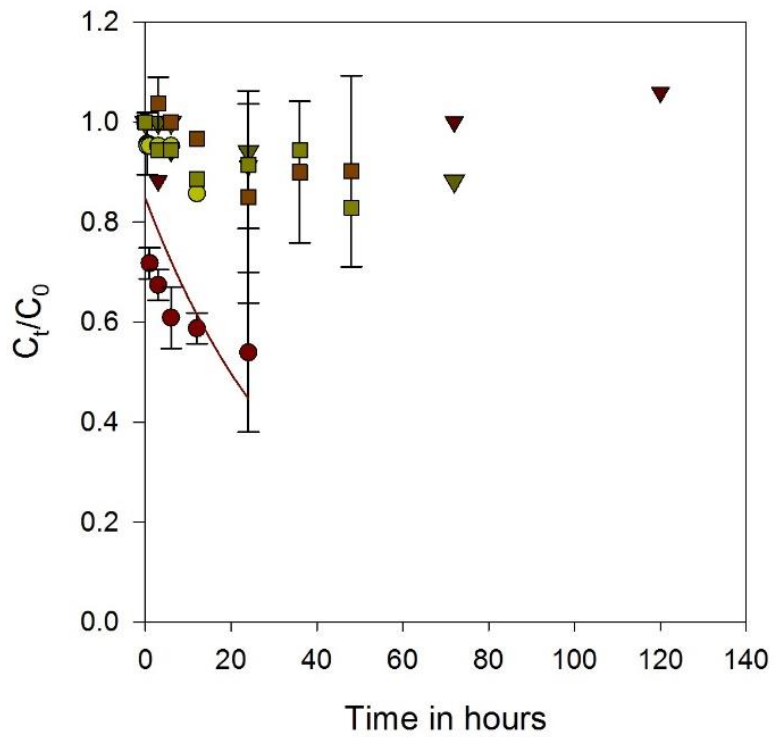

j. DEET - NV

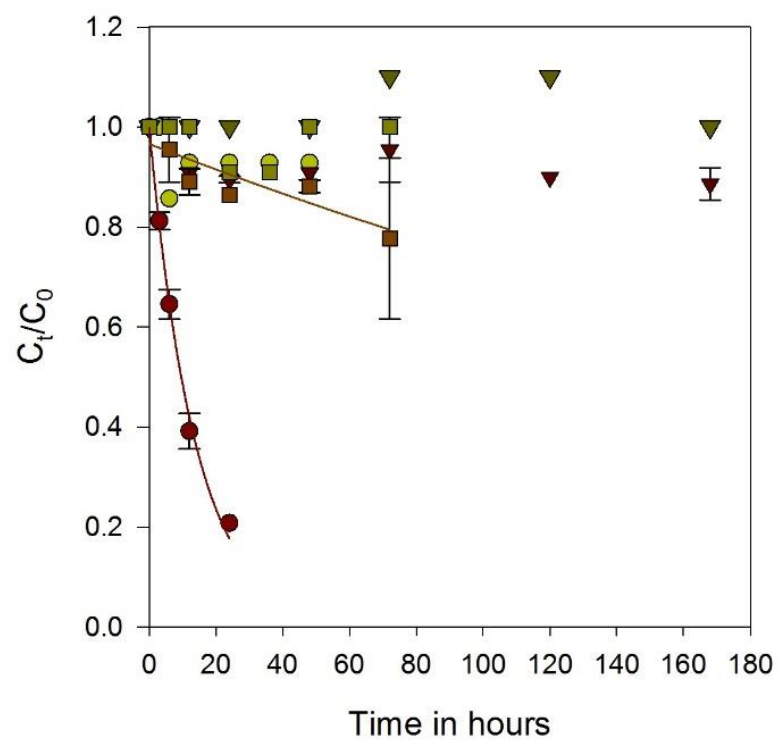

I. Benzotriazole - NV

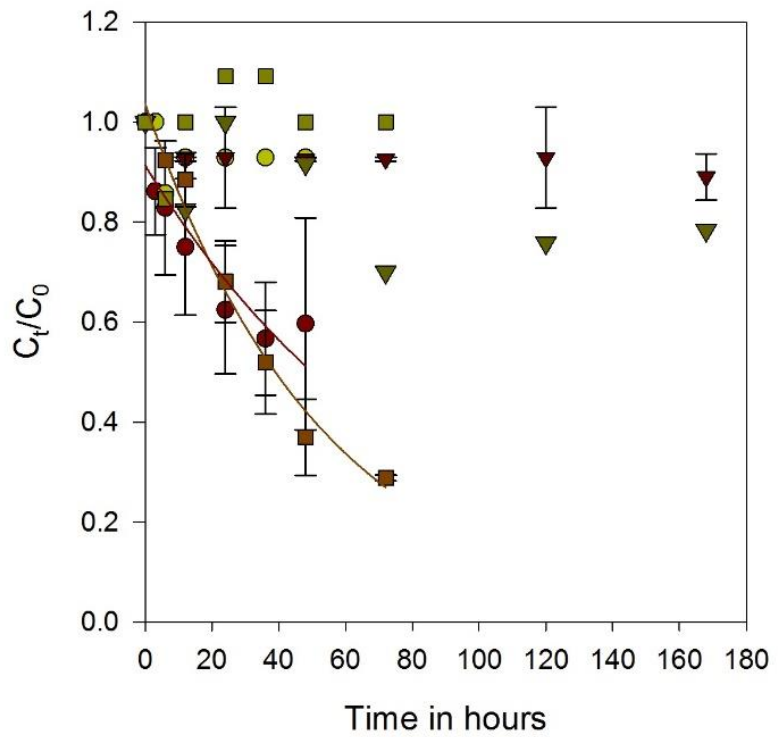
$\begin{array}{llll}\text { Aerobic - Biotic } & \boldsymbol{\nabla} & \text { Anaerobic - Biotic } \\ \text { Aerobic - Abiotic } & \nabla & \text { Anaerobic - Abiotic }\end{array}$

Figures S-4 (i, j, k, l). Biotransformation profiles of DEET, benzotriazole in biotic and abiotic reactors containing activated sludge from aerobic, anaerobic and anoxic redox conditions in $\mathrm{OH}$ and NV BNR treatment plants. 
m. Triclosan - $\mathrm{OH}$

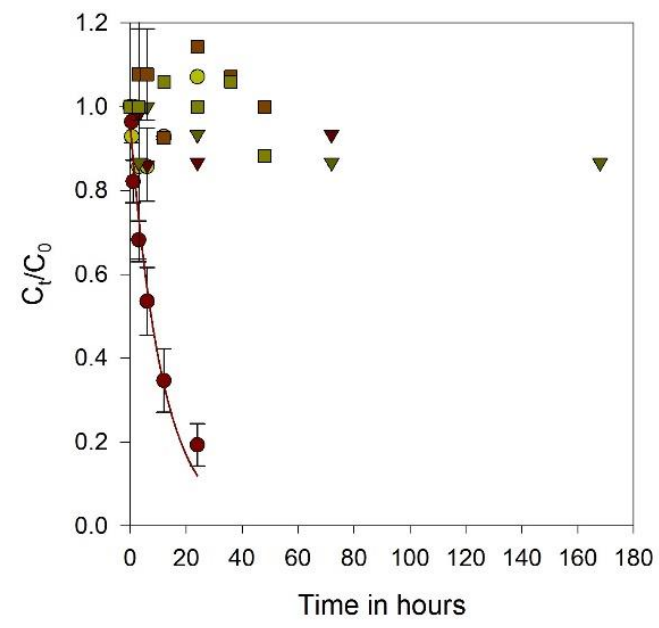

n. Triclosan - NV

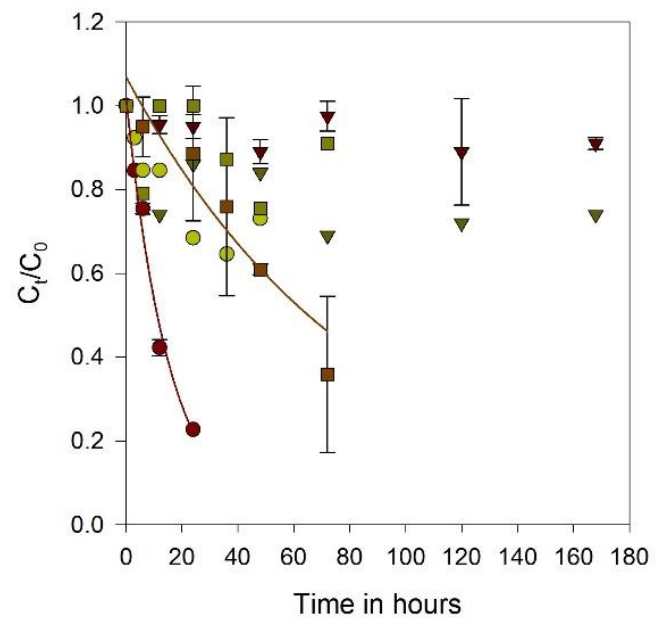

$\begin{array}{llll}\text { Aerobic-Biotic } & \boldsymbol{\nabla} & \text { Anaerobic - Biotic } \\ \text { Aerobic-Abiotic } & \boldsymbol{\nabla} & \text { Anaerobic - Abiotic } & \text { Anoxic - Biotic } \\ \text { Anoxic - Abiotic }\end{array}$

Figures S-4 (m,n). Biotransformation profiles for triclosan in biotic and abiotic reactors containing activated sludge from aerobic, anaerobic and anoxic redox conditions in $\mathrm{OH}$ and NV BNR treatment plants. 


\section{Analysis of Blanks and Controls}

The background concentration of the target compounds in the original activated sludge before spiking are provided in Figure S-5. Benzotriazole, a corrosion inhibitor, was found to be occurring at very high concentrations in the activated sludge samples from both treatment plants. The background concentration of triclosan was higher in $\mathrm{OH}$ when compared to $\mathrm{NV}$, whereas the background concentration of sulfamethoxazole was slightly greater in NV when compared to $\mathrm{OH}$. The background concentrations of atenolol, carbamazepine, DEET and trimethoprim were always close to or below the reporting limit. Little to no loss of the TOrCs was observed in the experimental control (DI water) reactors (Figure S-6), though some loss was observed for triclosan presumably due to sorption onto the reactor walls.

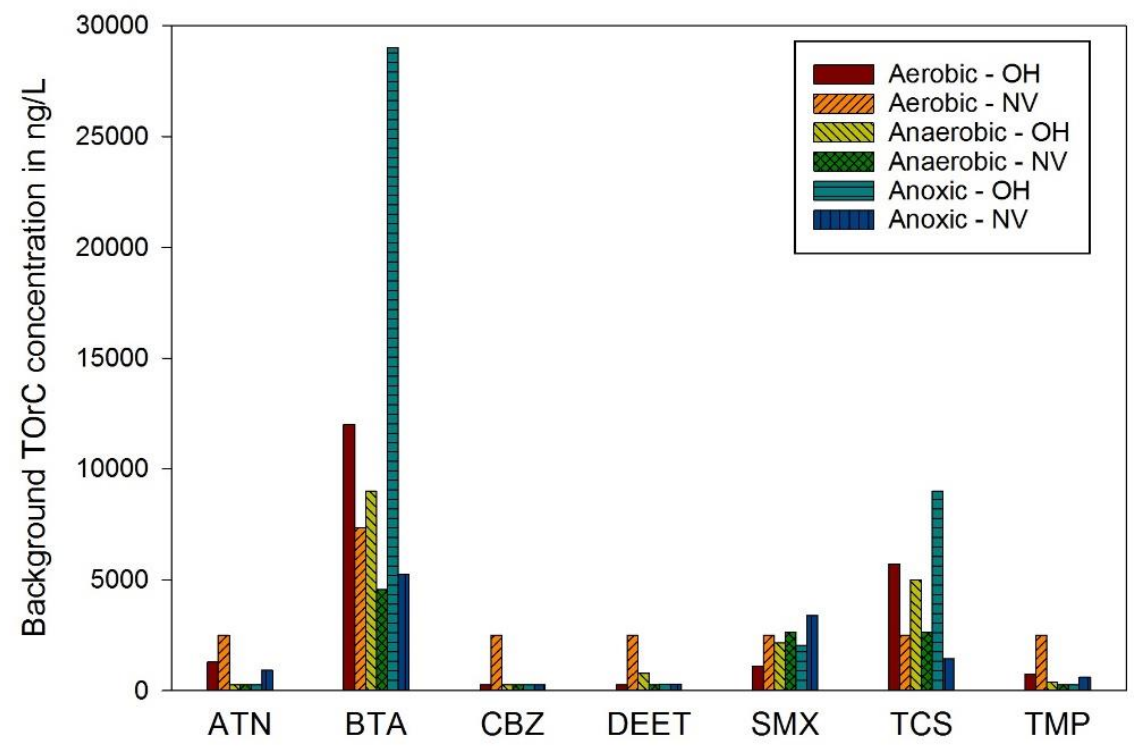

Figure S-5. TOrCs background concentrations in aerobic, anaerobic and anoxic activated sludge from $\mathrm{OH}$ and NV BNR treatment plants. Reporting limit $250 \mathrm{ng} / \mathrm{L}$ for all experiments except aerobic NV where it was $2500 \mathrm{ng} / \mathrm{L}$. 


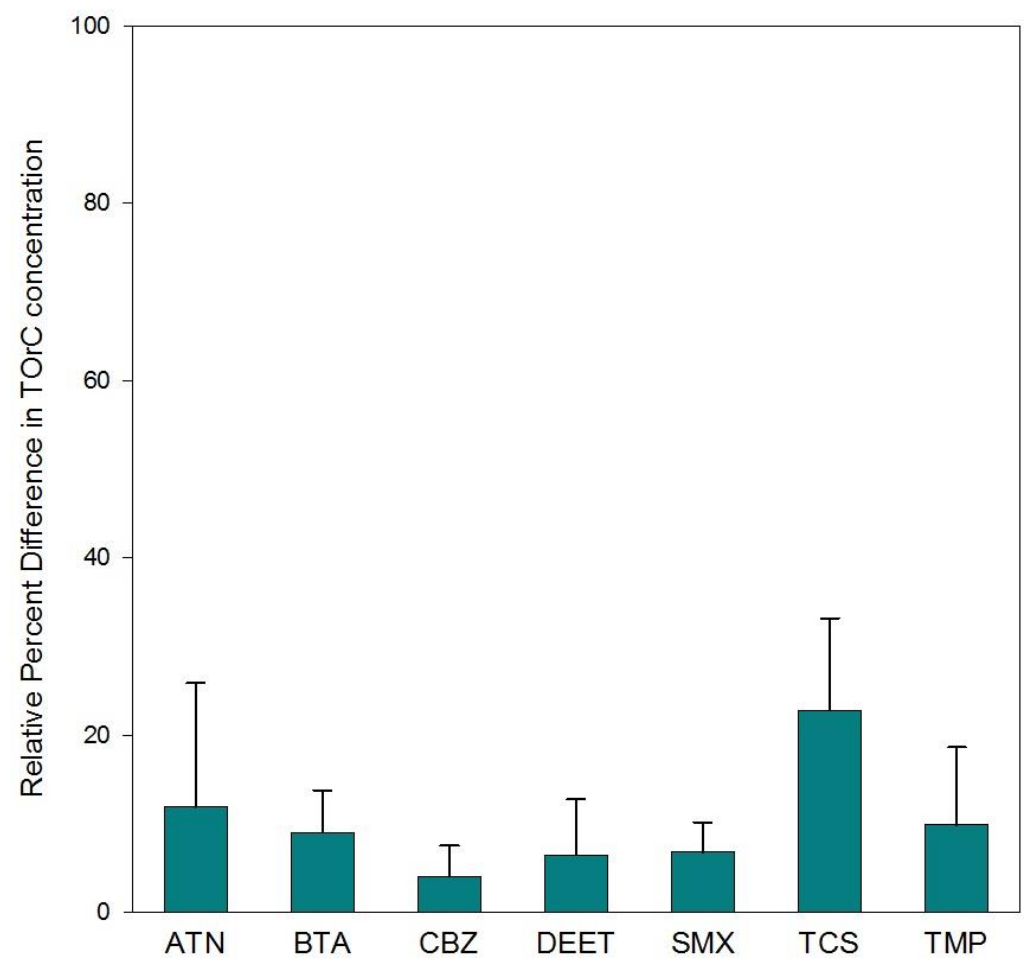

Figure S-6. Relative percent difference in TOrC concentrations between the initial and final time point in Experimental Control Reactor containing buffered DI water. Error Bars indicate the standard deviation in measurements from six biotransformation experiments.

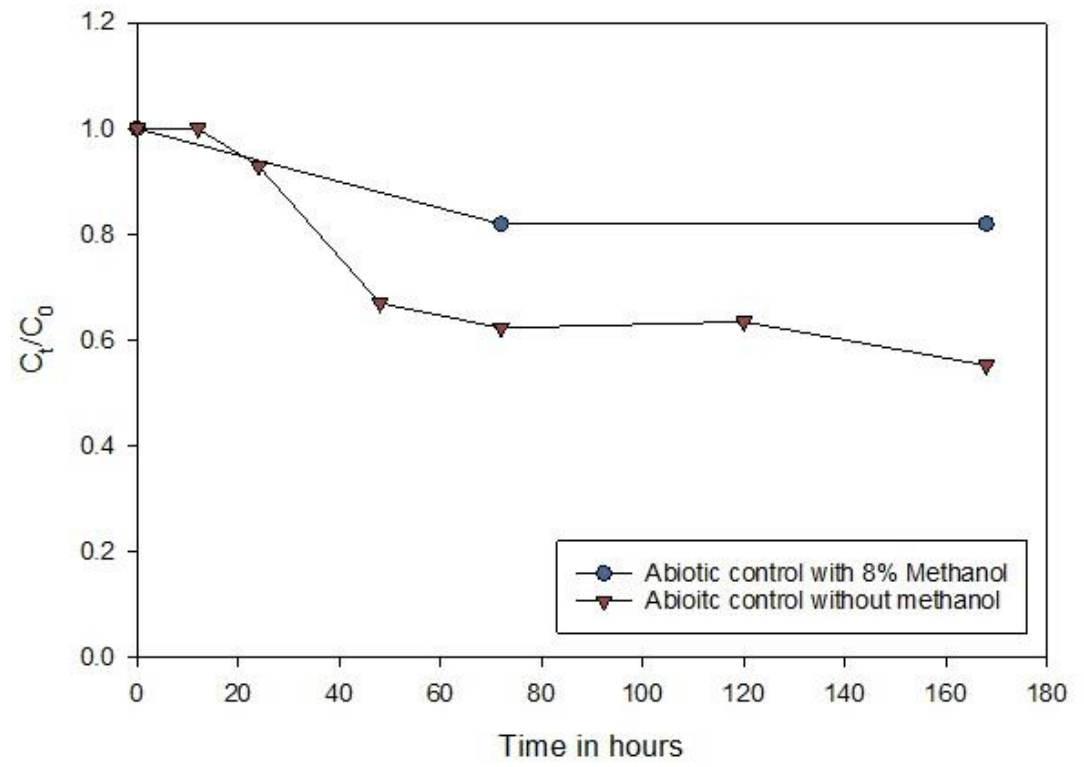

Figure S-7. Atenolol biotransformation inhibition in abiotic control containing $10 \mathrm{mM}$ biocide solution and $8 \%$ methanol. Sludge source - Anaerobic NV. 